\title{
Continuing upward trend in Mt Read Huon pine ring widths - Temperature or divergence?
}

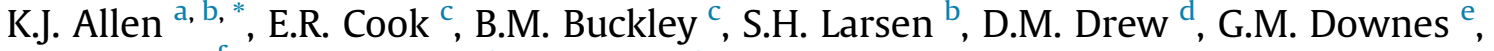 \\ R.J. Francey ${ }^{\text {f }}$, M.J. Peterson ${ }^{\mathrm{g}}$, P.J. Baker ${ }^{\mathrm{a}}$ \\ ${ }^{a}$ Department of Forest and Ecosystem Science, Melbourne School of Land and Environment, University of Melbourne, Richmond, Victoria, 3121, Australia \\ b School of Biological Sciences, Monash University, Clayton, Victoria, 3800, Australia \\ ${ }^{c}$ Tree Ring Laboratory, Lamont-Doherty Earth Observatory, Palisades, NY, 10964, USA \\ ${ }^{\mathrm{d}}$ Ecosytem Science CSIRO, Sandy Bay Tasmania, 7005, Australia \\ e Forest Quality, PO Box 293, Huonville, Tasmania, 7109, Australia \\ ${ }^{\mathrm{f}}$ Division of Marine and Atmospheric Research CSIRO, Aspendale, Victoria, 3195, Australia \\ g 351 Sheffield Rd, Acacia Hills, Tasmania, Australia
}

\section{A R T I C L E I N F O}

\section{Article history:}

Received 28 October 2013

Received in revised form

9 July 2014

Accepted 5 August 2014

Available online

\section{Keywords:}

Mt Read

Huon pine

Australia

Divergence

Time-dependence

Kalman filter

\begin{abstract}
A B S T R A C T
To date, no attempt has been made to assess the presence or otherwise of the "Divergence Problem" (DP) in existing multi-millennial Southern Hemisphere tree-ring chronologies. We have updated the iconic Mt Read Huon pine chronology from Tasmania, southeastern Australia, to now include the warmest decade on record, AD 2000-2010, and used the Kalman Filter (KF) to examine it for signs of divergence against four different temperature series available for the region. Ring-width growth for the past two decades is statistically unprecedented for the past 1048 years. Although we have identified a decoupling between temperature and growth in the past two decades, the relationship between some of the temperature records and growth has varied over time since the start of instrumental records. Rather than the special case of 'divergence', we have identified a more general time-dependence between growth and temperature over the last 100 years. This time-dependence appears particularly problematic at interdecadal time scales. Due to the time-dependent relationships, and uncertainties related to the climate data, the use of any of the individual temperature series examined here potentially complicates temperature reconstruction. Some of the uncertainty in the climate data may be associated with changing climatic conditions, such as the intensification of the sub-tropical ridge (STR) and its impact on the frequency of anticyclonic conditions over the Mt Read site. Increased growth at the site, particularly in the last decade, over and above what would be expected based on a linear temperature model alone, may be consistent with a number of hypotheses. Existing uncertainties in the climate data need to be resolved and independent physiological information obtained before a range of hypotheses for this increased growth can be effectively evaluated.
\end{abstract}

(c) 2014 Elsevier Ltd. All rights reserved.

\section{Introduction}

Uniformitarianism - the idea that the present provides the key to the past - is a fundamental assumption underlying palaeoclimatic reconstructions. In dendrochronology, this assumption is often simplified to assume that a relationship between a tree-ring chronology and a single climate variable (e.g. temperature) has

* Corresponding author. Department of Forest and Ecosystem Science, Melbourne School of Land and Environment, University of Melbourne, Richmond, Victoria, 3121, Australia. Tel.: +61 362375625.

E-mail address: Kathryn.Allen@unimelb.edu.au (K.J. Allen). remained effectively constant through time (Fritts, 1976). This simplification ignores other variables that may have important mediating effects on the relationship between temperature and tree-rings. The recent emergence of the "Divergence Problem" (DP) in relation to temperature, in numerous high latitude tree-ring sites in the Northern Hemisphere (Jacoby and D'Arrigo, 1995; Briffa et al. 2004; Wilson et al. 2007; Lloyd and Bunn, 2007; D'Arrigo et al., 2008; Grudd, 2008; D'Arrigo et al., 2009; Esper and Frank, 2009; Esper et al. 2010; Franceshini et al. 2012 amongst many others), potentially poses a significant challenge to uniformitarianism if uniformitarianism is considered in the limited sense described above. There are varying descriptions of divergence either implied or made explicit in the literature. Perhaps the most commonly cited 
example is ring widths/densities that, in the past three to four decades, are either no longer increasing at a rate commensurate with the rate of increase in temperature (e.g. Büntgen et al. 2008) or are decreasing as temperatures increase (e.g. D'Arrigo et al., 2004; Briffa et al. 2004). However, many studies have also identified sustained increases in ring width for the past three to four decades greater than expected based on temperature records (e.g. LaMarche et al. 1984; Paulsen et al. 2000; Wilmking et al. 2005; Gedalof and Berg, 2010). Both of these descriptions require only a 'decoupling' between temperature and radial growth in the most recent three to four decades such that the tree ring series does not fully retain the long term warming trend (divergence sensu Esper and Frank, 2009). Another, and far stricter position on divergence requires that any decoupling observed in the temperature-growth relationship in the most recent decades be directly attributable to a change in the primary limiting factor, for example, from temperature to moisture, in order for it to be considered divergence (pers. comm. K. Briffa, Climate Research Unit University of East Anglia; divergence sensu Briffa). The occurrence of this last case (e.g. Jacoby and D'Arrigo, 1995; D'Arrigo et al., 2008 and references therein) would constitute a much greater challenge to the broader uniformitarian assumption. Whether an observed decoupling in recent decades is identified more loosely as divergence sensu Esper and Frank or more strictly as divergence sensu Briffa, it could have profound implications for the development of high-quality annual-resolution temperature reconstructions from these chronologies (D'Arrigo et al., 2008; Esper and Frank, 2009) because models using these records and calibrated on the more recent period will under- or over-estimate the relationship between temperature and ring width outside this modern calibration period. This is a growing concern because several recent studies suggest that failure of treering series to continue to reflect warming in most recent decades is not restricted to high-latitude tree-ring sites (e.g., D'Arrigo et al., 2008; references therein; Martìn-Benito et al. 2010; Zhang and Wilmking, 2010). However, there are also numerous studies that have found no evidence for a recent decoupling of the temperature-growth relationship (e.g. Juday and Alix, 2012; Weijers et al. 2012; Young et al. 2012). In other words, the DP is neither ubiquitous nor uni-directional. It is also important to be aware that some studies refer to relationships between tree ring chronologies and climate that 'decouple' throughout their period of overlap as divergent (e.g. Zhang et al. 2009). This kind of relationship is probably better described as time-varying rather than divergent, and in this study, we describe such a relationship as timedependent, NOT divergent. The use of tree-ring chronologies with a time-dependent relationship with climate also has implications for climate reconstructions. The distinction between divergent and time-dependent is important because different underlying mechanisms may be responsible, therefore requiring a different approach in dealing with the issue.

A range of explanations specifically for the DP has been proposed. These explanations can be broadly grouped into three categories: methodological issues, site-level issues and global issues. Methodological issues include the choice of a linear temperature response model when a non-linear or threshold model might be more appropriate, end-effect bias caused by detrending misfits and trend distortions (D'Arrigo et al., 2008; Melvin and Briffa, 2008; Esper et al. 2010) and the 'slowgrower' survivorship bias that occurs when old and less climatically responsive trees are favoured for sampling, resulting in decreased growth in recent decades (Brienen et al. 2012a). Sitelevel issues can include local pollution effects on tree growth, differential responses of tree growth to minimum and maximum temperatures (Wilson and Luckman, 2002), lack of appropriate meteorological data for modeling the tree growth response to climate (D'Arrigo et al., 2008), undetermined stochastic differences (Martìn-Benito et al. 2010) and, as mentioned above, a change in the primary factor limiting growth at the site (Jacoby and D'Arrigo, 1995; divergence sensu Briffa). More global explanations related to climate include anthropocentrically induced warming leading to drought stress (D'Arrigo et al., 2008), $\mathrm{CO}_{2}$ fertilisation (LaMarche et al. 1984), global dimming (see D'Arrigo et al., 2008) and stratospheric ozone depletion (Briffa et al. 2004). While some of these potential explanations for the occurrence of the DP may be applicable to time-varying relationships, others specifically relating to changes that have only occurred in the most recent decades will not be.

To date, scrutiny of tree-ring chronologies for the DP has focused on Northern Hemisphere tree-ring sites and species, but there has been no concerted effort to assess whether the DP (or timedependence) is an issue in the more sparsely distributed long Southern Hemisphere tree-ring chronologies. The 3600-year Mt Read Huon pine (Lagarostrobos franklinii C.J. Quinn) chronology in Tasmania is the only Australian tree-ring record that has been successfully used to reconstruct warm season temperatures over the past millennium in its own right (Cook et al. 1991, 1992, 2000), and has been shown to be representative of large scale variability in the Southern Hemisphere latitudes influenced by the zonal westerlies (Cook et al. 2000). It has therefore been an important inclusion in IPCC analyses of changing temperatures in the Australasian sector of the Southern Hemisphere and has been used to help place the observed warming of recent decades in a long-term context (IPCC, 2007). When last reviewed, the Mt Read chronology did not include the past decade, which has been noted as the warmest since instrumental records began in many parts of the world (IPCC, 2007). Therefore, an update of the widely cited Mt Read chronology and an examination of whether it has fallen victim to divergence (whether sensu Esper and Frank or sensu Briffa) is imperative. Here we update the chronology, re-assess how well it represents modern day instrumental climate over the past century and examine it for signs of divergence.

\section{Data and methods}

Two or three $5 \mathrm{~mm}$ diameter cores from each of 18 trees were obtained from the $900 \mathrm{~m}$ ASL Tasmanian Mt Read site at the end of March 2010. Micro-core samples taken through the 2009/10 growing season indicated that cambial activity and xylem differentiation had ceased by the time of sampling (D. Drew, unpublished data) and that the final ring was complete. The updated chronology was constructed from the new samples and the previously crossdated material (Buckley et al. 1997; Cook et al. 2000) and is based on individual detrended series with a mean segment length greater than 500 years (Cook et al. 2000). All samples, including those previously obtained, were standardised (detrended and transformed into dimensionless indices; Fritts, 1976) using fitted negative exponential curves or linear trends of negative or zero slope, with the signal-free method applied to minimise trend distortion and end-effect biases in the final chronology (Melvin and Briffa, 2008). The use of negative exponential and linear detrending preserves low-frequency variations due to climate consistent with the 'segment length curse' (Cook et al., 1995b), but potentially loses some centennial time scale variability that had been preserved in the Mt Read chronology based on regional curve standardisation (Cook et al. 2000). Because our tests of divergence are based only on the outer 100 years of the chronology concurrent with meteorological data, the way we have standardised the chronology here versus the way done by Cook et al. (2000) should not have any impact on the possible detection of divergence in the Mt Read chronology. 
Cook et al. (1991, 1992) and Buckley et al. (1997) showed strong correlation between the Mt Read chronology and mean warm season (November-April) temperatures. Specifically, Cook et al. (1992) found the correlation between warm season temperatures (November to April) and the chronology over the 1885-1989 period to be $0.635(p<0.01)$. We therefore compared the updated Mt Read chronology with mean temperatures for these same months in order to check whether or not decoupling between growth and temperature in most recent decades has occurred. We have, however, expanded on the initial comparison with mean temperatures by using four long time series of mean temperature that are now available. The 'Cook series', developed by Cook et al. (1991) and based on the longest continuous temperature series available for locations in Tasmania (Hobart, Launceston - the Launceston record used is composed of two Launceston stations and Low Head: all low elevation $(<200 \mathrm{~m}$ ASL)) has been updated for this study. This series was the only one of the four series examined below that was available when Cook et al. (1991) first established the relationship between the Mt Read chronology and warm season temperature and subsequently reconstructed past temperature (Cook et al., 1991, 1992, 1996, 2000; Buckley et al. 1997). Both the SILO (extracted 12/9/2013) (Jeffrey et al. 2001), and AWAP (26 h) data (Jones et al. 2009) are gridded data sets for Australia based on $0.05^{\circ} \times 0.05^{\circ}$ resolution grids. The coarserresolution CRU (3.2) data set is based on a $0.5^{\circ} \times 0.5^{\circ}$ grid (Mitchell and Jones, 2005). To more readily enable visual comparison of the temperature series on the same graph (SILO and AWAP have been adjusted for elevation, but the Cook series has not, and therefore reflects the higher temperatures at low elevation), all temperature series and the chronology were converted to z-scores (Fig. 1a). Temperature data series extend from 1911 to 2009. To check whether the Mt Read chronology has become limited by warm season precipitation (Fig. 1b) rather than by warm season

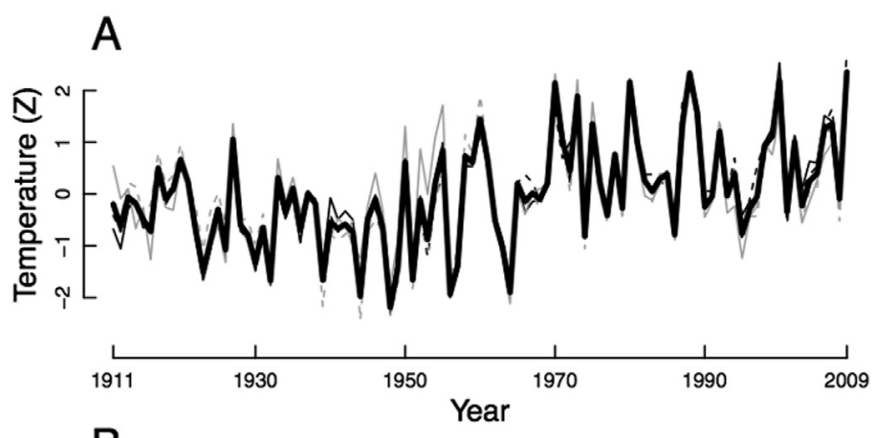

B

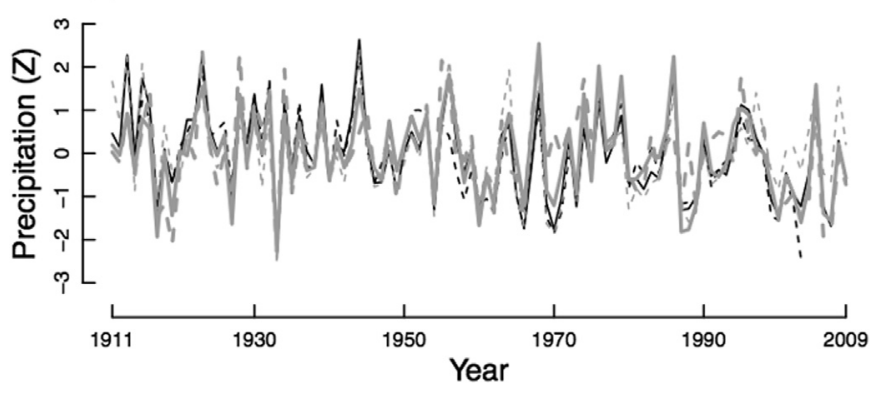

Fig. 1. A. Standardised mean warm season temperature data. Thin black line is AWAP series, black dashed line is Cook series; grey solid line is CRU temperature series and grey dashed line is SILO data series. Thick black line is averaged temperature data (all four temperature series). B. Precipitation for Mt Read. Thin black line is AWAP, black dashed line is Lake Margaret, grey dotted line is CRU, grey line is GPCC and grey dashed line is SILO. CRU, AWAP, GPCC and SILO cover the 1911-2009 period while data for Lake Margaret cover 1913-2003. temperature (i.e. check for divergence sensu Briffa), five sets of precipitation data were also obtained for testing purposes: AWAP, CRU, SILO and GPCC gridded data sets and the nearest long-term station, at Lake Margaret, approximately $20 \mathrm{~km}$ south of Mt Read. The CRU and GPCC data obtained are based on a $0.5^{\circ} \times 0.5^{\circ}$ grid resolution. These data were also converted to z-scores over the period in common amongst all series for the purpose of visual comparison. Because the Lake Margaret site only began recording in 1913 and there was a considerable portion of missing data after 2002, only the 1913-2002 period is shown for Lake Margaret in Fig. 1b.

Four popular methods previously used to identify decoupling of temperature and growth in recent decades include: visual comparison of tree ring series and temperature series (e.g. Jacoby and D'Arrigo, 1995; Briffa et al. 1998; Martìn-Benito et al. 2010); comparison of response/correlation functions or regression models for two or more separate periods (Cook et al. 1987; Leal et al. 2008; D'Arrigo et al., 2009; Andreu-Hayles et al. 2011a); changing spatial correlations (D'Arrigo et al., 2009) and examination of simple running correlation or regression coefficients between temperature and tree-ring series (e.g. Briffa et al. 2004; Coppola et al., 2012; Gurskaya et al. 2012; Franceschini et al. 2012). Here we instead use the Kalman Filter (KF; Visser and Molenaar, 1988) to examine whether the relationship between the Mt Read chronology and each of our four temperature and five precipitation series has significantly changed in recent decades (Visser and Molenaar, 1988). As formulated here, the dynamic KF calculates estimates based on a weighted average of the predicted value and its uncertainty and the actual measured value (Harvey, 1989). The identification of whether a constant relationship model is a better fit to the data than one with a coefficient that changes over time is determined objectively by maximum likelihood, which is a big advantage over ad hoc running correlation/regression methods. The KF also has an advantage over other techniques in that it incorporates information about uncertainty in its estimates. It has previously been used in a number of other dendrochronological studies to examine changes in relationships between climate and tree-rings or between different climate reconstructions (e.g. Visser and Molenaar, 1988; Cook and Johnson, 1989; Jacoby and D'Arrigo, 1995; Wilson et al. 2010; Cook et al. 2013). Because temperature has been found to be the dominant driver of ring width increases in the Mt Read chronology (Buckley et al., 1997), the KF was applied with temperature as the predictor of ring widths for the 1911-2009 period. In addition, Briffa et al. (1998) and Büntgen et al. (2008) have previously observed differences in relationships between high frequency series and those between low frequency series. We have therefore tested the relationships between the unfiltered Mt Read chronology and the unfiltered temperature for stability and then compared filtered data series after applying a 10-year smoothing spline (Cook and Peters, 1981). Both the 10-yr high pass and 10-year low pass data were tested using the KF. The 10year spline was used in preference to, for example, a longer spline (e.g. 20 years) due to the relatively short climate data series available to us. In order to check that our use of the signal-free framework to develop the chronology has not resulted in a substantial difference in the relationship with climate, we have tested the relationship between temperature and four versions of the Mt Read chronology: the standardised chronology based on ratios, standardised chronology based on residuals, the signal-free chronology based on ratios and the signal-free chronology based on power-transformed residuals.

The use of the KF as described in the preceding paragraph enabled us to check whether or not the DP, or general timedependence, is present but it did not allow us to check whether there had been a change in the factor most limiting to growth at the 

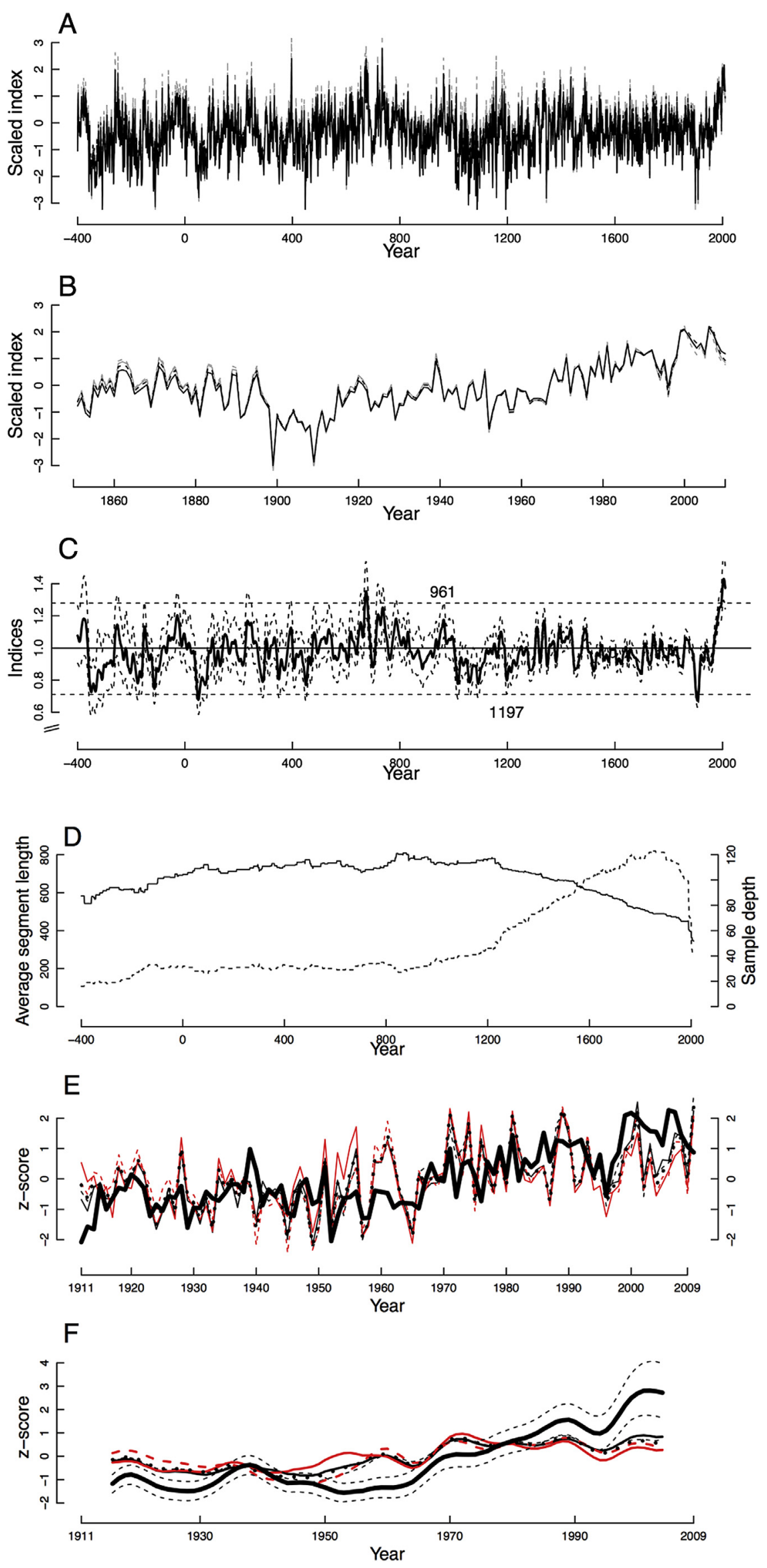
site. We therefore also tested the relationship between the four different versions of the chronology and each of the precipitation data sets over the period in common between the precipitation data sets (1913-2002) using unfiltered, high-pass and low-pass data. If the relationship with precipitation has become more limiting in recent decades, an increasingly positive association between precipitation and the chronology would be expected.

\section{Results}

Annual ring-width growth since the 1960s has continued to increase in the Mt Read Huon pine (Fig. 2a,b) as warm season temperatures have continued to increase (Fig. 1a). Growth (inferred mean warm season temperatures) in the two most recent decades is the highest over the last 2400 years (Fig. 2a) although wider confidence intervals prior to AD1000 mean there is no significant difference $(p<0.05)$ between the inferred temperatures of the most recent decades and the periods centred on AD 700 and AD 961 (Fig. 2c). Nevertheless, as inferred by the chronology, the most recent period is statistically the warmest on record for the past 1048 years. Interestingly, high inferred temperatures for both the AD 700-centred period and the most recent period coincide with high counts of macroscopric charcoal at Frenchman's Cap in Tasmania's central west (pers. comm. M. Fletcher University of Melbourne). Although the early 20th Century was the coldest period for 800 years (Fig. 2a), it is not unprecedented; inferred temperatures for the period centred on AD 1197 are statistically indistinguishable from those in the early 20th Century. The period centred on AD 50 is the coldest period, on average, inferred by the chronology (Fig. 2c). A visual comparison of the climate data and the chronology (Fig. 2e) suggests that the rate at which ring widths have generally increased since the mid 1990s has been greater than the rate at which temperatures increased. Bootstrapped confidence intervals (95\% interval) for the smoothed data (Fig. 2f) also indicate that the increase in ring widths has been greater than the increase in mean warm season temperature over the past decade. These results are consistent with a partial decoupling of growth and temperature, or as Esper and Frank (2009) explain, the inability of the tree rings to fully retain the long term upward trend in temperatures.

Figs. 3-5 show the KF results for the four different versions of the Mt Read chronology. The solid line represents the dynamic regression model coefficient as determined by the $\mathrm{KF}$ and the dashed lines are the $2 \sigma$ limits. If the solid line is horizontal, this indicates that the relationship is time-stable whereas a nonhorizontal line indicates that the relationship is not time-stable. If the $2 \sigma$ limits enclose the zero line, this indicates a relationship not significantly different from zero. If both $2 \sigma$ limits are above (below) the zero line, then the relationship is deemed positive (negative). Whether or not changes in the relationship over time are significant can be assessed by a comparison of the bias corrected Akaike Information Criterion (AIC) for the linear model and the dynamic regression model (Van Deusen, 1990). If AIC KF model - AIC KF linear $<-2$ then the non time-stable model is a better fit to the data than the constant coefficient model (see Table 1). If the relationship changes from positive to negative, this presents more serious challenges than the case in which the relationship varies from being indistinct from zero to positive (negative), because not only is the relationship non-constant, but even its sign is reversible.

Several important points can be drawn from Figs. 3-5. First, the difference in the KF traces for the different versions of the chronology is trivial, illustrating the robustness of the Mt Read chronology to slight differences in chronology development methodology. Second, results differ depending on which climate data was used. Thirdly, and most pertinently, there is no clear evidence of a decoupling between temperature and growth that only occurs in the most recent decades. This is most apparent for the low pass data (Fig. 5) and the unfiltered AWAP and Cook data (Fig. 3) for which the KF traces indicate changing relationships between temperature and growth throughout the twentieth century. Therefore, rather than our KF results indicating divergence sensu Esper and Frank (2009), we suggest that they demonstrate timedependent relationships (the nature of time-dependence differing based on the climate data used) but NOT divergence. In this case, solely focusing on decoupling at the end of series would be to pay unequal attention to other instances of decoupling (Esper and Frank, 2009).

For the relationships shown in Figs. 3-5, time-dependence between the chronology and temperature data was only considered present if all versions of the chronology were assessed as timedependent. The time-dependent model for the relationship between the chronology and each of the AWAP and Cook warm season temperature series was assessed as superior to the constant coefficient model (Table 1; AIC KF model - AIC KF linear $<-2$ ), and the pattern of time-dependence differed depending on the temperature data used. In the case of the Cook data, the sign of the coefficient varies from indistinct from zero to positive. The relationship between the chronology and the unfiltered AWAP data is strongest at the start and towards the end of the series, weakening slightly in most recent years. The $2 \sigma$ limits for the early part of the century are relatively wide for the Cook series that has a relatively strong relationship at the start of the century but which then becomes indistinct from zero until the 1970s. Like the AWAP series, the relationship between the Cook series and chronology weakens in most recent years. Time-dependence is therefore clearly a concern for the AWAP and Cook data, particularly for the Cook data since the relationship varies from being positive to indistinct from zero. Greatest differences in the traces occur in the 1940s/50s and at the ends of the traces.

The high-pass relationships between the Mt Read chronology and all temperature series examined here are positive and constant (Fig. 4). The relationship between the high-pass SILO temperature data and the Mt Read ring-width chronology appears to weaken slightly towards the end, although a constant coefficient model is superior to one with a time-varying coefficient (AIC KF model - AIC $\mathrm{KF}$ linear $>-2$; Table 1 ). In all cases, the high-pass relationships are very similar to one another. In contrast, none of the relationships between the low-pass series and the chronology are constant and

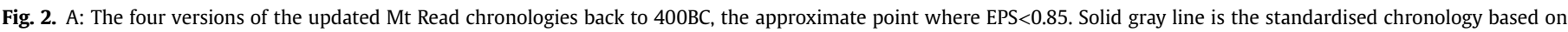

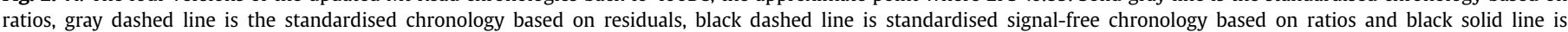

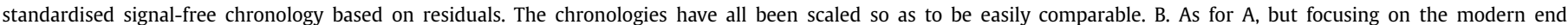

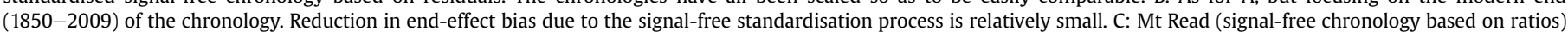

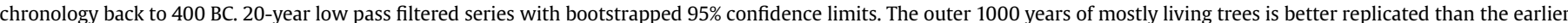

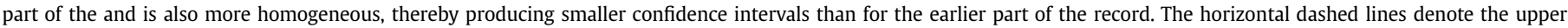

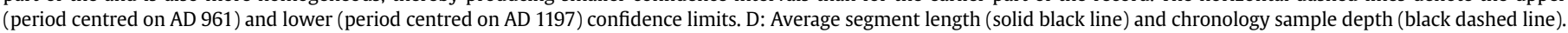

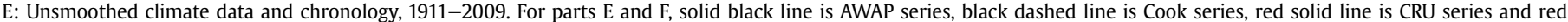

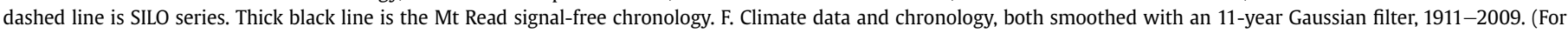
interpretation of the references to colour in this figure legend, the reader is referred to the web version of this article.) 

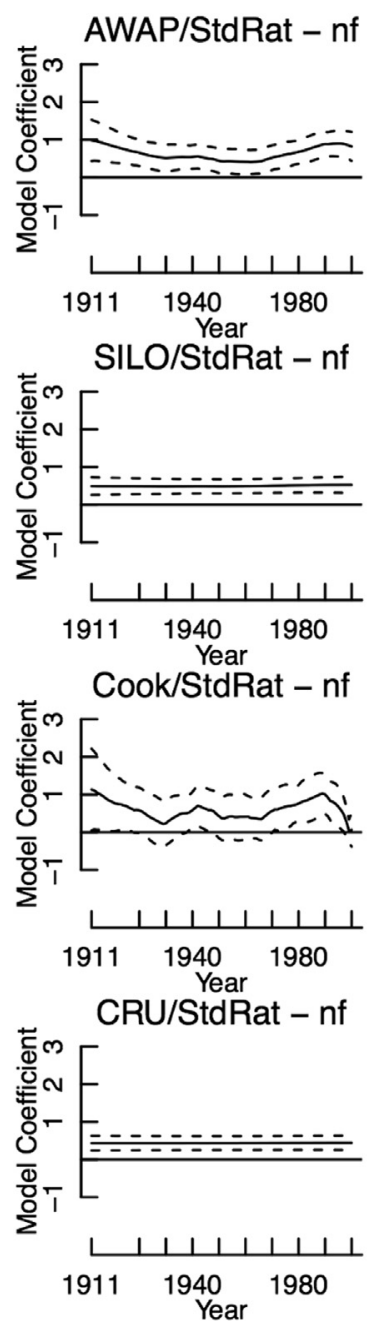
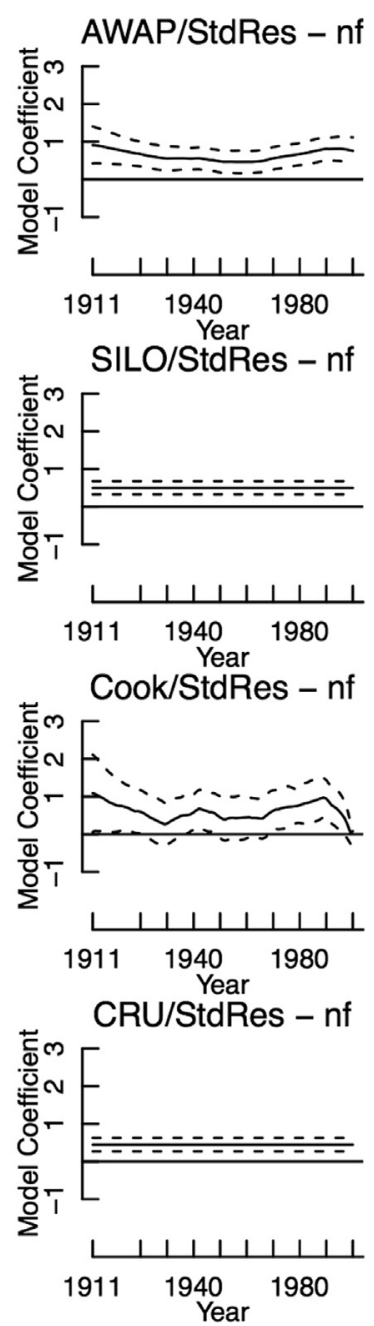
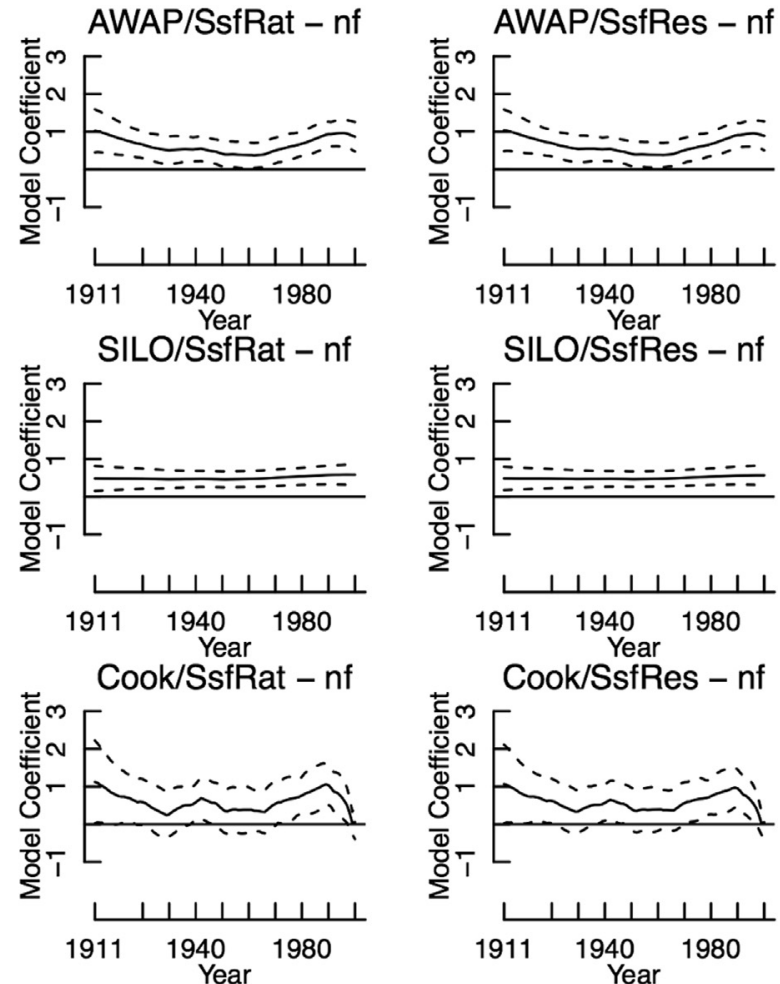

CRUSsfRat - nf
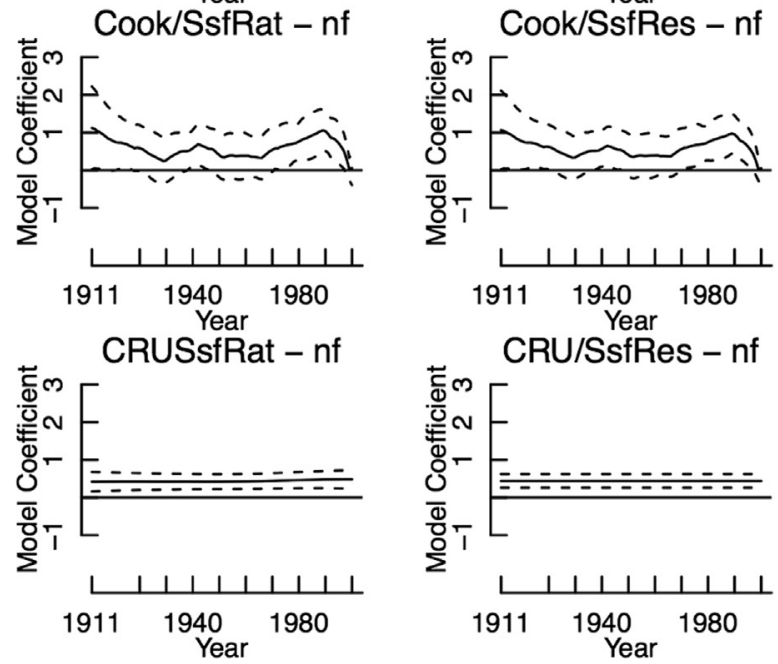

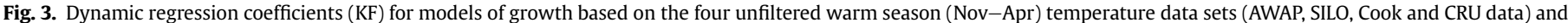

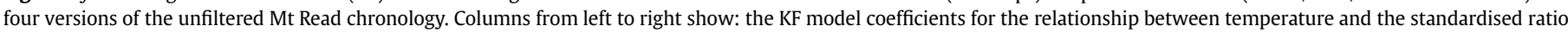

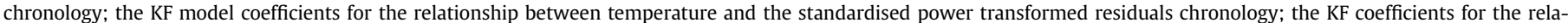

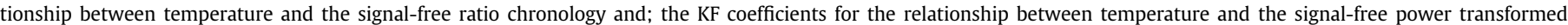

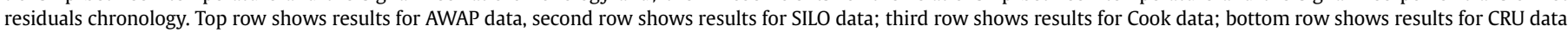
Dashed lines represent $2 \sigma$ limits.

this time-dependence is also significant (Table 1). Notably, the relationship between the low-pass chronology and low-pass AWAP data has remained mostly positive over the past 100 years (exception of 1935-1940 for three of four chronology versions), whereas those between the low-pass chronology and the remaining low-pass temperature series oscillate between positive and indistinguishable from zero, or negative in the case of the Cook series (Fig. 5). In all cases, the relationship has become less positive in the most recent years of the record and this weakening is most evident for the relationships between the chronology and the SILO and Cook series. As an aside, it is interesting to note that the low frequency trend in the CRU temperature data differs most and that in the AWAP data differs least from the trend in tree ring width (Fig. 2f). While this may seem somewhat at odds with the similarity in the $\mathrm{KF}$ traces for the respective low pass temperature data (Fig. 5), a closer inspection reveals that the uncertainty limits for the two series overlap (Fig. S1), meaning that their relationships are not statistically $(p<0.05)$ different over this period (indeed, the relationships are statistically the same for much of the last century).

The relationships between the chronology and the five precipitation data sets illustrate general time-dependence for both low- pass and unfiltered data (Fig. S2; Table S1). For unfiltered data and for all data sets except SILO, the relationship is generally not significantly different from zero until the mid-late 1980s when it becomes negative, implying that decreasing precipitation has become less limiting to radial growth. The high-pass relationships are constant over time (Fig. S3). Unlike the variable relationships seen for the low pass temperature data, the low-pass relationships with the various precipitation data (exception of SILO data) sets are very similar to one another over time (Fig. S4). The overall conclusion is that there is no sign of warm season moisture sensitivity emerging in the Mt Read chronology even with increasing warmth and decreasing precipitation occurring in recent years (Fig. 1): Mt Read remains a sufficiently moist place for Huon pine growing there.

\section{Discussion}

The decoupling of growth and temperature in most recent decades at Mt Read is not limited to most recent decades only, but occurs throughout the period of instrumental records, its nature depending on the climate record used. This time-dependence is 

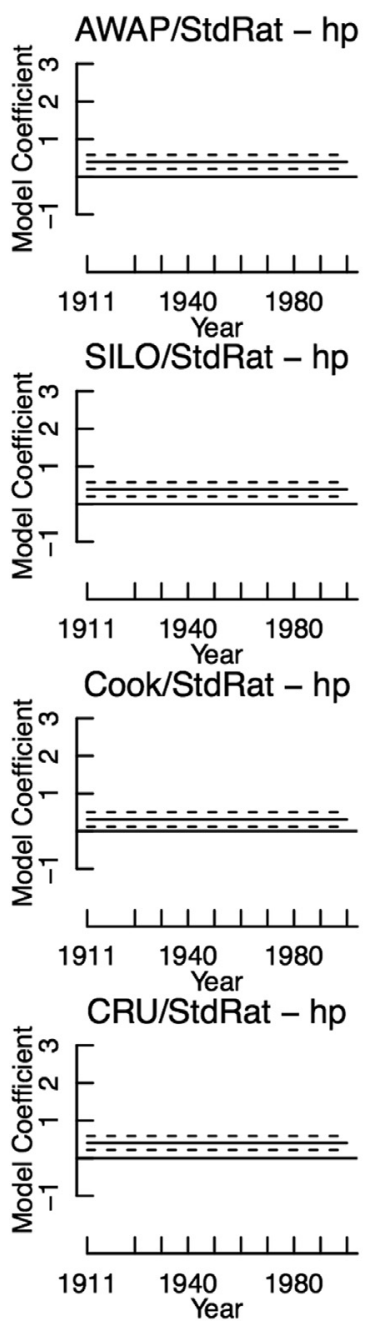
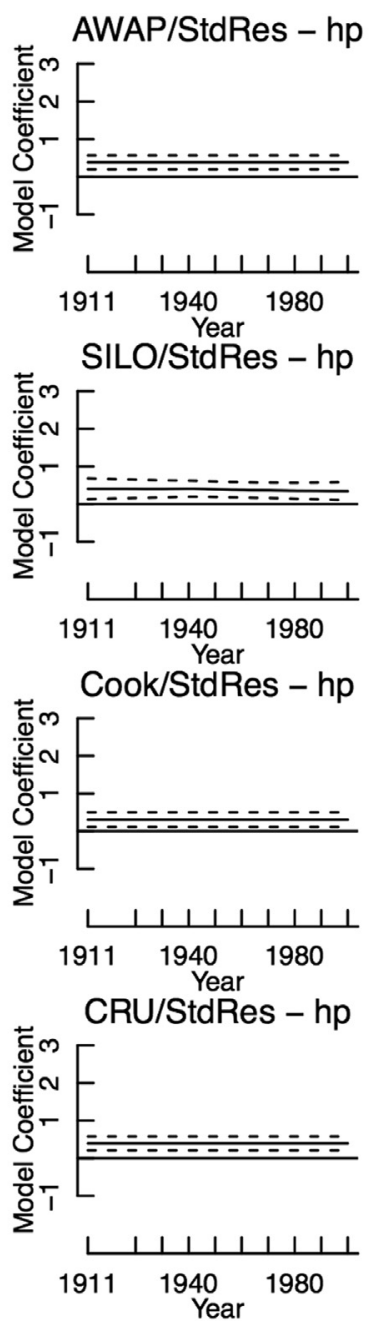

Fig. 4. As for Fig. 3, but for high pass filtered data.
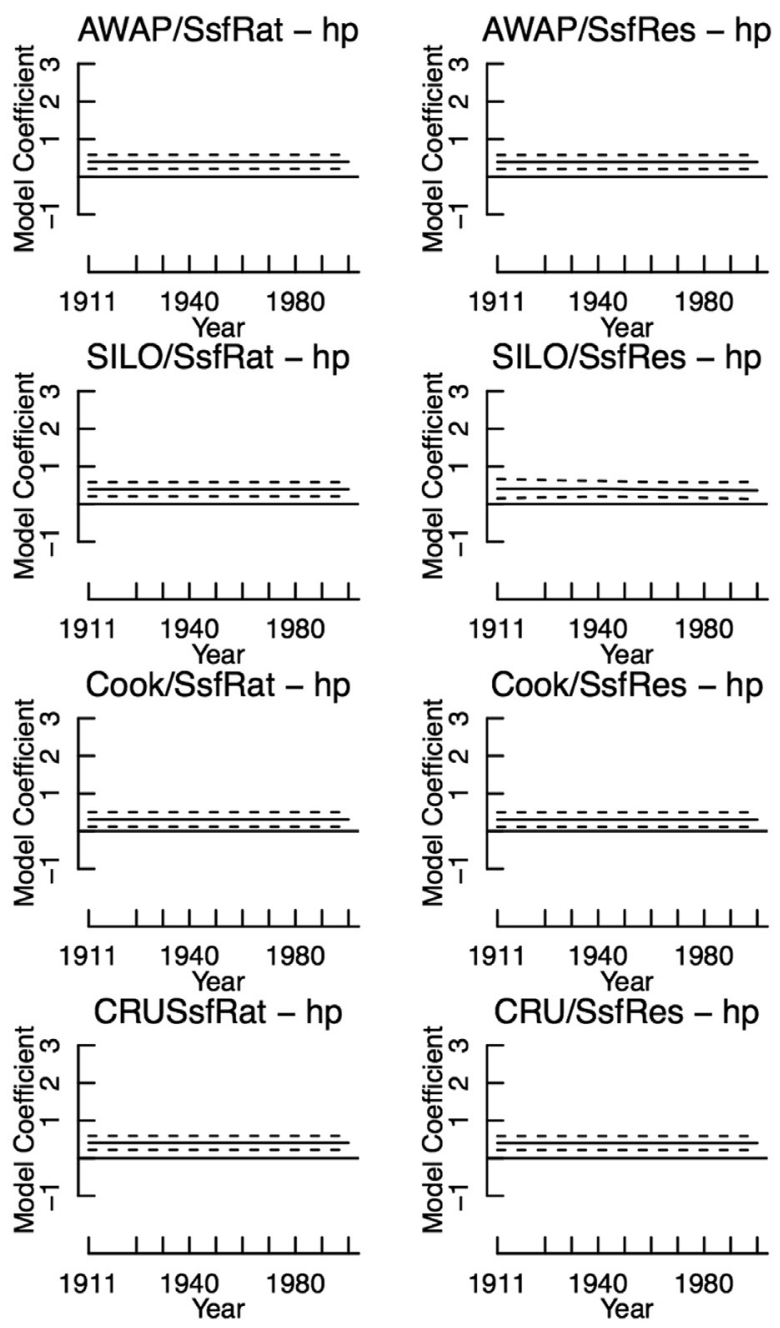

most apparent for the low pass data. Time-dependence between climate and tree-ring time series is as important as the issue of divergence itself because it too has serious implications for a reconstruction based on such a relationship. Framed by uncertainties relating especially to the climate data, our discussion below focuses on the time-dependence issue, firstly with reference to data filtering, secondly on the selection of the climate data to use, and thirdly, on the greater than expected (based on temperatures; Fig. 2e,f) increase in ring widths since the 1960s.

\subsection{Does using filtered data present a solution to time-dependence?}

Our results for Mt Read (regardless of climate data set used) suggest that time-dependence can generally be avoided by highpass filtering (10-year spline) data. However, use of high-pass filtered data only will effectively prohibit identification and analysis of important low frequency climate variability itself. Changes in low frequency relationships with climate variables are certainly relevant for the Mt Read chronology because at least two previous studies support the existence of such low (decadal or lower) frequency variability. Cook et al. (1996) demonstrated stronger correlations between the Mt Read chronology and surface temperatures to the west of Tasmania from 1880 to 1927 and to the east of Tasmania from 1950 to 1989. Allen et al. (2013) found that the spatial extent of significant correlations between the Mt Read chronology and southeast Australian temperatures varied for the 1955-2009 and 1901-1954 periods.

\subsection{Selection of climate data}

Because the temperature series have all been tested against the same tree-ring record, the results shown in Figs. 3-5 demonstrate not only time dependence, but also considerable variation (although not always statistically significant $(p<0.05)$ ) in the temperature records themselves. This illustrates considerable uncertainty surrounding the precise nature of mean temperature variation over the past 100 years and how that variation in individual records relates to the Mt Read tree-ring chronology. As D'Arrigo et al. (2008) and Esper and Frank (2009) point out, uncertainties in the climate data used to assess the presence or absence of divergence (or time dependence) can be a critical problem. Some of the climate data issues highlighted in the literature as plausibly affecting stability of relationships with tree-ring chronologies include: distance of climate stations from the treering site, difference between the elevation of the climate station and tree-ring site, differences in rates of increase in maximum and minimum temperatures (Wilson and Luckman, 2002), and inhomogeneities in the climate data (D'Arrigo et al., 2008;; Esper et al. 2010). While most studies of divergence to date have used individual station records (e.g. Jacoby and D'Arrigo, 1995; D'Arrigo 


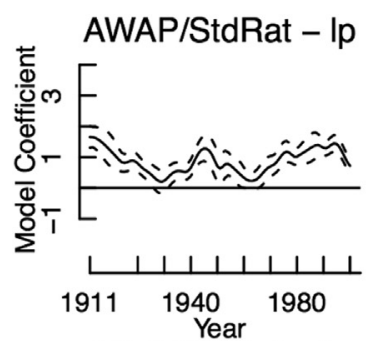

SILO/StdRat - Ip
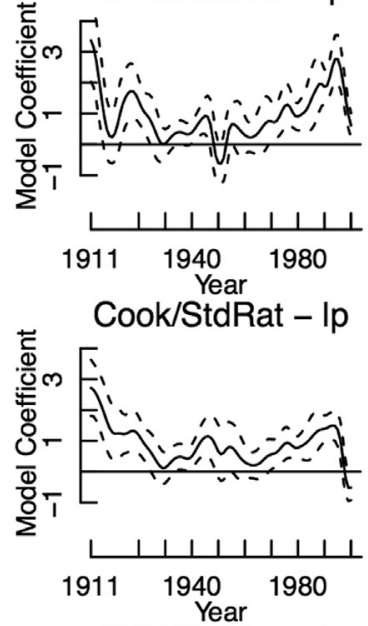

CRU/StdRat - Ip

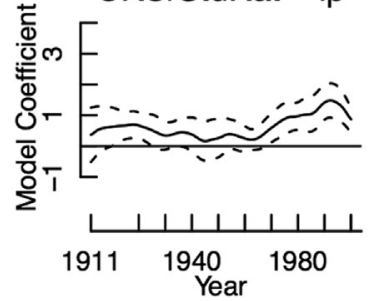

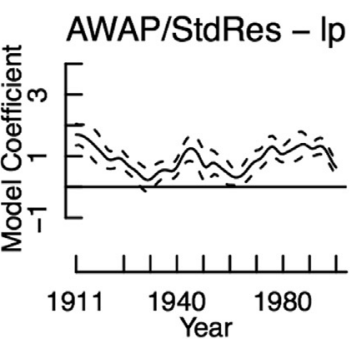

SILO/StdRes - Ip

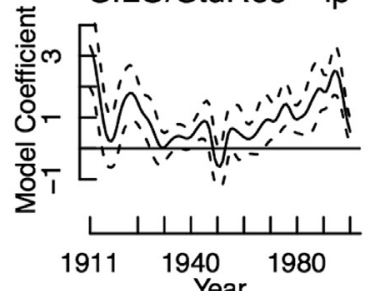

Cook/StdRes - Ip

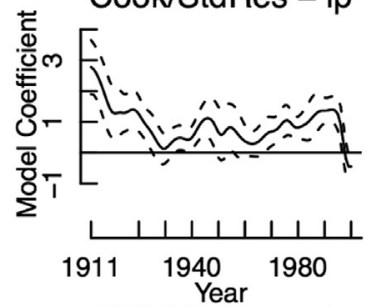

CRU/StdRes - Ip

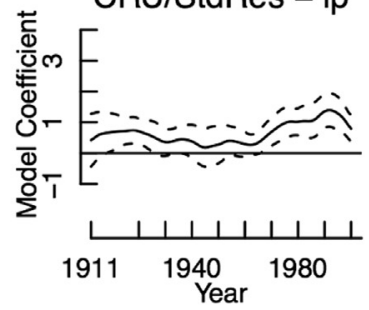

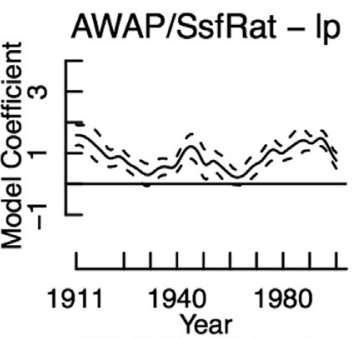

SILO/SsfRat - Ip

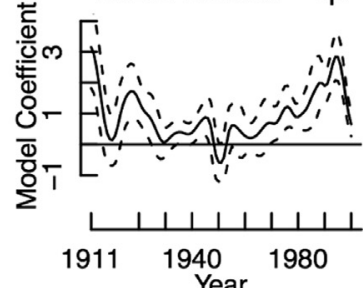

Cook/SsfRat - Ip

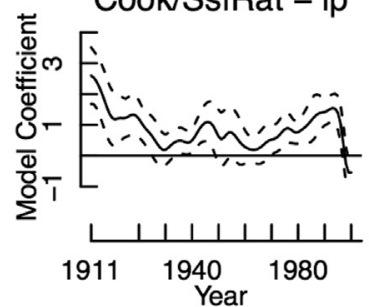

CRUSsfRat - Ip

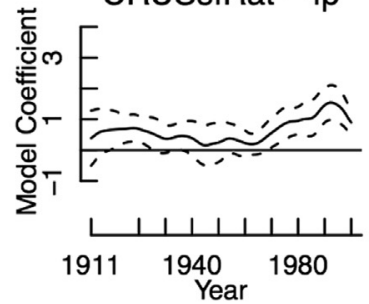

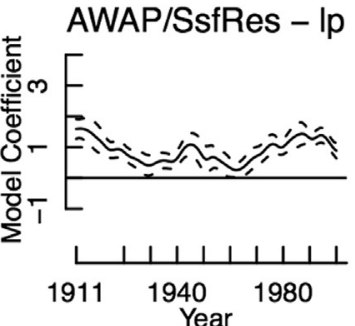

SILO/SsfRes - Ip

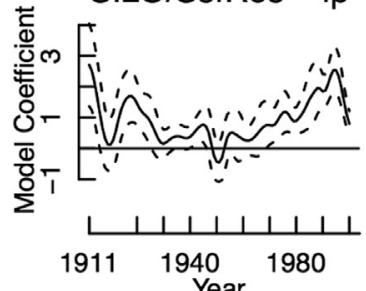

Cook/SsfRes - Ip

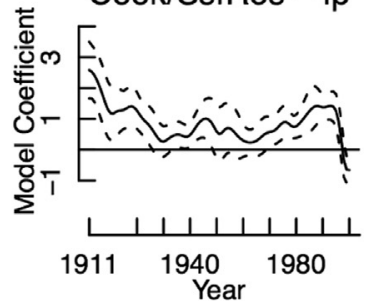

CRU/SsfRes - Ip

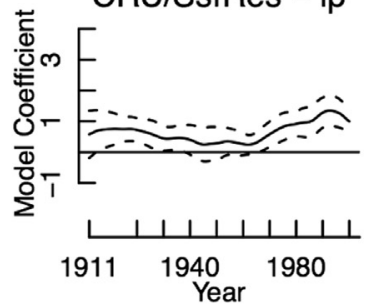

Fig. 5. As for Fig. 3 but for low pass filtered data.

et al., 2004; Frank et al. 2007; Esper and Frank, 2009; Esper et al. 2010), availability and use of gridded data sets (e.g., Climate Explorer, http://climexp.knmi.nl/) for a range for climate variables is increasing and they have been used in some studies of divergence
(Briffa et al., 2002a\&b). The same range of issues identified for station data (e.g. Esper and Frank, 2009; Esper et al. 2010) also affects gridded data sets because any systematic errors or homogeneity problems in the station data will be propagated into the

Table 1

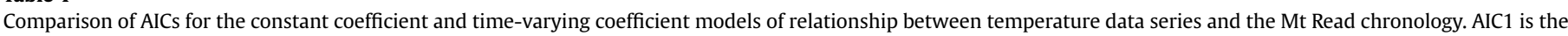

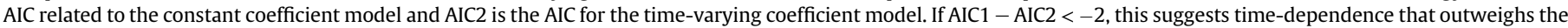
penalty function of the AIC, and therefore that time-dependence is significant. Figures in bold indicate cases in which AIC1 - AIC2 $<-2$.

\begin{tabular}{|c|c|c|c|c|c|c|c|c|c|}
\hline & & \multicolumn{2}{|c|}{ Standardised ratio crn. } & \multicolumn{2}{|c|}{ Standardised residual crn. } & \multicolumn{2}{|c|}{ Signal-free ratio crn. } & \multicolumn{2}{|c|}{ Signal-free residual crn. } \\
\hline & & AIC1 & AIC2 & AIC1 & AIC2 & AIC1 & AIC2 & AIC1 & AIC2 \\
\hline \multirow[t]{3}{*}{ AWAP } & Unfiltered & -47.85 & -54.64 & -47.94 & -51.63 & -48.62 & $-\mathbf{5 7 . 5 8}$ & $-\mathbf{5 0 . 0 2}$ & $-\mathbf{5 8 . 7 0}$ \\
\hline & High pass & -14.79 & -14.79 & -13.74 & -13.74 & -15.09 & -15.09 & -14.59 & -14.59 \\
\hline & Low pass & -132.09 & -234.74 & -139.13 & -234.93 & -134.66 & -240.22 & -145.39 & -243.18 \\
\hline \multirow[t]{3}{*}{ SILO } & Unfiltered & -26.54 & -24.56 & -26.60 & -26.60 & -26.51 & -25.54 & -26.34 & -25.54 \\
\hline & High pass & -13.83 & -11.87 & -12.74 & -11.31 & -14.15 & -14.15 & -13.53 & -11.95 \\
\hline & Low pass & -51.24 & -150.74 & -53.48 & -144.87 & -51.49 & -151.81 & -53.09 & -135.88 \\
\hline \multirow[t]{3}{*}{ Cook } & Unfiltered & -20.35 & -37.70 & -21.61 & -37.59 & -20.04 & -38.06 & -19.33 & -35.46 \\
\hline & High pass & -6.19 & -6.19 & -5.64 & -5.64 & -6.35 & -6.35 & -6.03 & -6.03 \\
\hline & Low pass & -52.77 & -139.14 & -60.07 & -146.40 & -51.64 & -137.85 & -51.04 & -137.04 \\
\hline \multirow[t]{3}{*}{ CRU } & Unfiltered & -19.17 & -17.05 & -20.16 & -20.16 & -18.96 & -17.27 & -19.34 & -19.34 \\
\hline & High pass & -15.76 & -15.76 & -14.67 & -14.67 & -16.03 & -16.03 & -15.50 & -15.50 \\
\hline & Low pass & -37.19 & -58.72 & -41.66 & -61.27 & -37.84 & -61.16 & -42.96 & -61.96 \\
\hline \multirow[t]{3}{*}{ Avg. Series } & Unfiltered & -36.68 & -36.68 & -37.12 & -35.25 & -36.90 & -39.16 & -37.68 & -40.02 \\
\hline & High pass & -15.83 & -15.83 & -14.61 & -14.61 & -16.15 & -16.15 & -15.50 & -15.50 \\
\hline & Low pass & -84.31 & -217.21 & -89.03 & -216.31 & -85.56 & -217.50 & -92.66 & -209.04 \\
\hline
\end{tabular}


gridded data sets. In addition, a change in the number and spatial distribution of individual station records used to produce the gridded data back in time can lead to inhomogenous behavior of the affected record. It should, however, be noted that development of the gridded data sets used here explicitly included consideration of issues such as homogeneity, station data completeness, and methods to deal with missing data (Jeffrey et al. 2001; Mitchell and Jones, 2005; Jones et al. 2009). An additional consideration for gridded data sets is the different interpolation procedures used for each of these gridded data sets, as each will have its own strengths and weaknesses (Jeffrey et al. 2001; Mitchell and Jones, 2005; Jones et al. 2009). Further, small methodological changes in interpolation procedures for gridded data sets may also lead to some differences in different versions of each of the gridded data sets.

Essentially, there are two sets of issues that need to be scrutinised with regard to choosing a particular temperature data set. First and foremost, it is important to consider the available climate data sets based on factors independent of their relationship with the climate proxy data. For gridded data sets, one of these factors will be the grid resolution. The CRU grid data is less well resolved than AWAP or SILO and the Cook series is not gridded but based on three widely distributed low elevation meteorological stations (Cook et al. 1991). Crude spatial resolution is likely to be problematic where topography is highly variable (as in western Tasmania), and particularly so for precipitation data. Large temporal and spatial gaps in individual station records from which interpolated surfaces are derived are similarly problematic. There are many short term ( $<40$ years) climate records (www.bom.gov.au) prior to the 1960s in western Tasmania due to the transient nature of mining and hydro-electric construction settlements in the region. This will clearly affect all the gridded surfaces used in this study. However, a number of relatively short (including some high elevation) data sets have been incorporated into the AWAP data and Jones et al. (2009) argue that the AWAP maximum temperatures are a considerable improvement over other available maximum temperature data.

Differences in elevation between tree ring sites and climate stations are a further concern. Adjustments are often made to the climate data in an attempt account for this difference in elevation. The Cook series makes no adjustment for elevation while both the AWAP and SILO data include adjustments for elevation based on a standard environmental lapse rate (ELR, $0.0065{ }^{\circ} \mathrm{C} \mathrm{m}^{-1}$ ) that is assumed to have remained constant over time. Even though adjustments for elevation may improve the accuracy of temperature data, they may not account for conditions encountered at certain sites over time. Specifically, the AWAP data uses lapse rate information based on the 1970-2000 period (D. Jones, pers. comm. Bureau of Meteorology) and will not incorporate any information about declining lapse rates that may have occurred due to more rapid warming at high compared to low elevations (Thompson et al. 2003). In addition, a constant ELR relies on a well-mixed atmosphere. This assumption is questionable under anticyclonic conditions in which temperature may decrease through the boundary layer to about 800-1100 mASL at which height a marked temperature inversion typically occurs (Kirkpatrick et al. 1996). Above this inversion the air mass is warmer and drier than below it. Increased frequency of anticyclonic conditions over the Mt Read site in recent decades (cf. Larsen and Nicholls, 2009, Fig. 6a), resulting in more frequent inversions at this level, may mean that temperatures at the site have been warmer than predicted by the ELR in recent decades. Topographical influences on lapse rates may also be important (Minder et al. 2010) but cannot be readily incorporated into large gridded data sets without considerable site-specific research. On the basis of factors independent of the climate proxy alone (e.g. a lack of adjustment for elevation (Cook), relatively crude

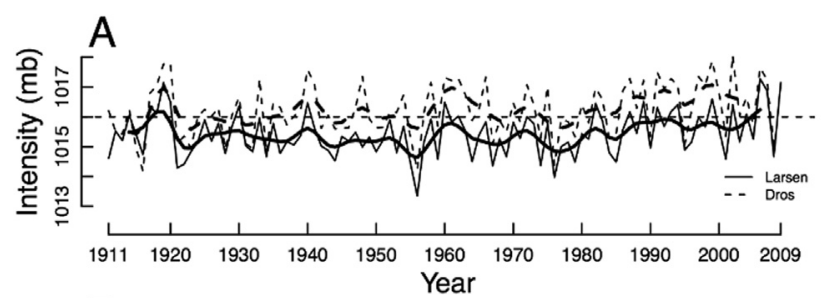

B
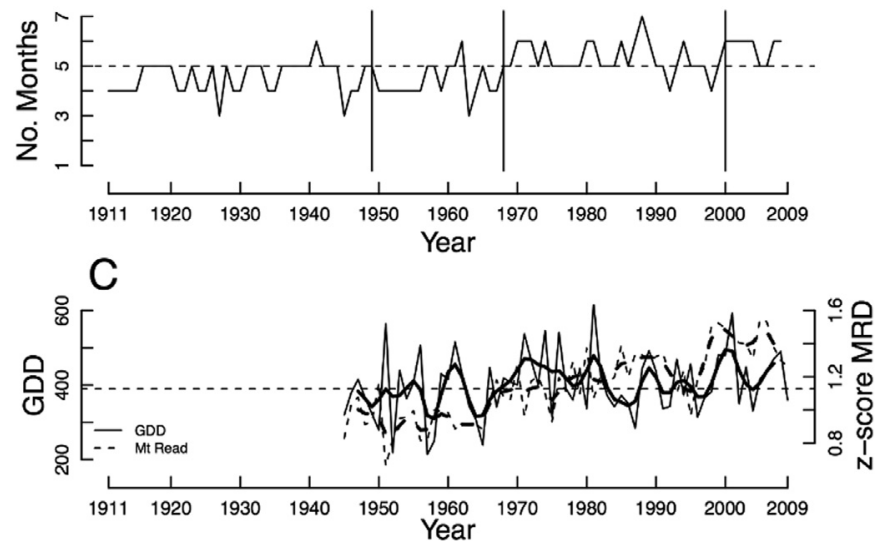

Fig. 6. A. Intensity of the subtropical ridge (STR) using two L-indices. The Larsen index is the extended Larsen and Nicholls (2009) L-index based on the global gridded MSLP data set, Had2SLP2r (Allan and Ansell, 2006) and was constructed for Australian longitudes $\left(110^{\circ}-155^{\circ} \mathrm{E}\right)$. Wasyl Drosdowsky kindly provided the 'Dros' STR intensity series, an extension of the index developed by Drosdowsky (2005). Dashed horizontal line is median pressure (Dros). B. Number of months for which mean temperature $\geq 8{ }^{\circ} \mathrm{C}$ (AWAP data). Vertical lines separate whole period into segments with visibly different median number of months with mean temperatures $>8{ }^{\circ} \mathrm{C}$ (median number of months are: 5,4,5,6 respectively). Horizontal line shows overall median. C. Growing degree days since 1945 based on data for Butler's Gorge (highest elevation station with longest temperature record for central Tasmania) adjusted for Mt Read elevation using the standard ELR of $0.0065 \mathrm{C} / \mathrm{m}$ and a threshold temperature of $8{ }^{\circ} \mathrm{C}$. Butler's Gorge is located in central Tasmania whereas the greatest increase in growing season length has been noted for the north of the state (see the Bureau of Meteorology website for growing season information: http://www.bom.gov.au/climate/change/index.shtml\#tabs=Climate-change-trackeramp;tracker=extremes-trend-mapsamp;tQ [map] $=$ GrSLamp;tQ[period $]=1970$ ).

resolution in a topographically variable area (CRU), and improved maximum temperature estimation in the AWAP data), it may be better to consider using either the SILO or AWAP data instead of the CRU or Cook series.

Notwithstanding these potential limitations, it is also necessary, when multiple climate data sets are considered to be equally appropriate and of equal quality for reconstruction purposes, that the temporal relationship between the proxy record (in this case, the Mt Read ring-width chronology) and target climate variable be examined. If a relationship varies from being positive (negative) to negative (positive), a reconstruction based on it will be unreliable. In this study, the generally positive and more consistent relationship between the unfiltered Huon pine chronology and unfiltered CRU, SILO and AWAP data suggests those data sets are preferable to the Cook series (Fig. 3). For high pass data, constant coefficient models are superior to time-varying models in all cases (Fig. 4; Table 1), so there is no obvious choice of high pass climate data set to use. For the low-pass data, the generally positive relationship between the chronology and either of the AWAP or CRU data over the last 100 years makes them preferable to the Cook or SILO series, although time-dependence remains problematic in a reconstruction context. As an aside, it is interesting to note that the relationship between maximum and minimum temperatures in the SILO data set differs from that in all other data sets (discussed 
Table 2

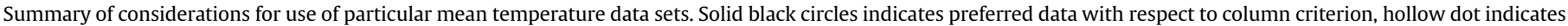

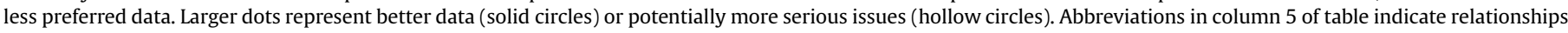
between unfiltered (UF), high-pass filtered (HP) series. Mxt is maximum temperature and mnt is minimum temperature.

\begin{tabular}{|c|c|c|c|c|c|}
\hline \multirow{2}{*}{$\begin{array}{l}\text { Mean temperature } \\
\text { data series }\end{array}$} & \multicolumn{5}{|l|}{ Issue } \\
\hline & Resolution & $\begin{array}{l}\text { Changing no. of stations/ } \\
\text { changing stations }\end{array}$ & Elevation adjustment & $\begin{array}{l}\text { Stable relationship } \\
\text { with chronology }\end{array}$ & Other comments \\
\hline AWAP & $\bullet$ & O & O & $\mathrm{HP}$ & $\begin{array}{l}\text { Mxt estimates improved } \\
\text { Note version used }\end{array}$ \\
\hline SILO & - & O & O & UF, HP & $\begin{array}{l}\text { Mxt/Mnt relationship (Fig. S4-5) } \\
\text { Note version used }\end{array}$ \\
\hline Cook & O & O & ○ & HP & Lack of adjustment for elevation \\
\hline CRU & O & O & o & UF, HP & Note version used \\
\hline Average & Mixed & O & Mixed & UF, HP & Possible issues with simple averaging \\
\hline
\end{tabular}

further below), suggesting caution in the use of the SILO data would be wise (Figs S5 and S6). Table 2 contains a summary of identified issues in the various climate data sets.

Given that none of the individual climate series are ideal for temperature reconstruction based on the Mt Read chronology, we have also calculated an average of the four mean warm season temperature series. These data have once again been filtered with a 10-year spline and unfiltered, low-pass and high-pass series tested using the $\mathrm{KF}$ in the same manner as done for individual series. Although the relationship between the unfiltered chronology and unfiltered averaged temperature is not entirely time-stable (Fig. 7; S7), a constant coefficient model is preferable to a model with a time-varying coefficient for two of the four chronology versions, while the time-varying model is only marginally better in the remaining two cases (Table 1 ). The relationship between the highpass series is time-stable. The time-dependence for the averaged unfiltered data is likely due to low-frequency time-dependence indicated for the individual temperature series (Figs. 3-5), and also present in the averaged series (Fig. S7). This averaged (unfiltered) temperature series therefore represents an alternative series that could be used for temperature reconstruction, although attention to issues related to averaging data based on different interpolation methods may require further assessment (Gotway and Young, 2002).

\subsection{Possible reasons for the rapid increase in ring widths since the $1960 \mathrm{~s}$}

The rapid increase in ring widths observed in the chronology after about 1960 (Fig. 2e,f) must be considered in the context of uncertainties in both in the climate data (described above) and the tree-ring chronology. With respect to the Mt Read chronology, it is clear that only very small differences in the versions of the final chronology exist (based on either ratios or residuals). On the basis of there being only relatively small uncertainties in the tree-ring chronology, it is worthwhile examining possible causes of increased growth relative to warm season temperatures at Mt Read because other studies have previously identified increased growth relative to temperature at other sites. Fig. $2 \mathrm{f}$ also shows that the increase in all temperature series, including the average temperature series, does not match the rate of increase in ring widths. Growth increases in recent decades at temperature-limited sites in both the Southern and Northern Hemispheres (Peterson et al., 1995; Nicolussi et al. 1995; Villalba et al., 1997; Paulsen et al. 2000) may have serious implications for temperature reconstructions because it is these temperature sensitive sites with long-lived species that are typically used for reconstructions. Although the most recent decades are not the only instance of decoupling between the Mt Read chronology and warm season temperatures over the 99-year period examined (Figs. 3 and 5), we consider this most recent period first because it matches the timing of observed decoupling in tree-ring/climate relationships in many Northern Hemisphere chronologies and some climate observations are only available for the latter part of the 20th Century. Several potential explanations for growth increasing faster than would be expected based on temperature alone have previously been proposed. These include: increased availability of nitrogen to trees from atmospheric sources and via warming of the soil (Grace et al. 2002; Strömgren and Linder, 2002); changing precipitation patterns (D'Arrigo et al., 2004); sampling methodology (Brienen et al. 2012a); the $\mathrm{CO}_{2}$ fertilisation effect (LaMarche et al. 1984; Gedalof and Berg, 2010); temperatures that are increasing faster at higher than lower elevations (e.g. Seidel and Free, 2003; Bradley et al. 2009); amplification of increases in high elevation temperatures affecting the formation of new tissue (Grace et al. 2002 and references therein) and differential increases in maximum and minimum temperatures (Wilson and Luckman, 2003). For Mt Read there are also uncertainties surrounding the temperature data and the possibly inappropriate use of a constant ELR, the impact of increased intensity of the subtropical ridge (STR) and more
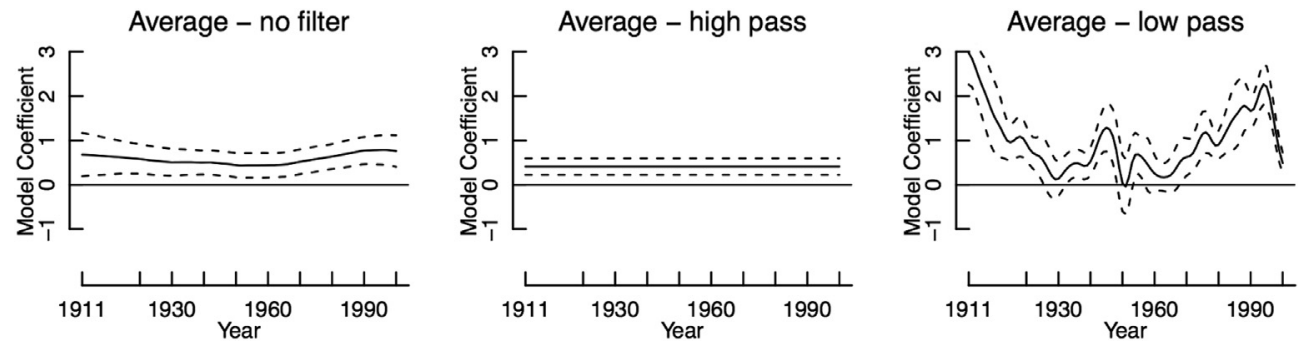

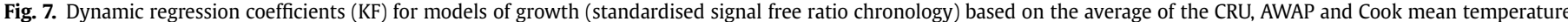

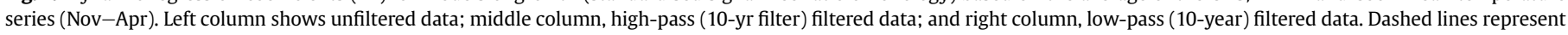
$2 \sigma$ limits. Data extends from 1911 to 2009 . Results for all versions of the chronology are shown in Fig. S7. 
frequent occurrence of an inversion layer at approximately the same elevation as the Mt Read site.

Neither the increased nitrogen availability hypothesis nor the hypothesis that temperatures are increasing faster at higher elevations can be assessed for the Mt Read site due to lack of appropriate data. The absence of high elevation (>800 $\mathrm{m} \mathrm{ASL}$ ) temperature records in Tasmania that extend from at least 1950 to present impedes comparison of high and low elevation temperatures. Due to regionally high topographical variability, gridded data are inappropriate for such a comparison. The 'big tree selection' sampling bias (Brienen et al. 2012a) can occur if only the largest and fastest growing living trees are sampled. Because the Mt Read chronology consists of samples from both living and dead trees and is based on a large proportion of available stems over $10 \mathrm{~cm}$ in diameter, it is unlikely that this is relevant to the patterns observed here. Given the extreme sensitivity of Huon pine to moisture stress (Brodribb and Hill, 1998; Brodribb and Cochard, 2009; Drew unpublished data), it is highly unlikely that decreasing precipitation at Mt Read (Fig. 1b) would promote growth. Although the KF traces indicate a relationship between growth and precipitation that is becoming negative (unfiltered data; Fig. S2), this is consistent with the inverse relationship between Tasmanian precipitation and temperature, and is most likely a reflection of the relationship with temperature over this period rather than indicative of decreasing importance of precipitation itself. Further, if the recent decrease in precipitation had indeed become more limiting to growth on Mt Read, an increasingly positive response to precipitation would be expected.

It is plausible that, given the unusually high elevation of the Mt Read Huon pine site, a greater increase in maximum temperatures than minimum temperatures may be responsible for the accelerated increase in ring widths compared to mean temperatures (Wilson and Luckman (2003). Fig. S5 indicates that warm season maximum temperatures, obtained from the four temperature data sets used in this study, and an average of these, have indeed increased more than warm season minimum temperatures over the past 100 years. Fig. S6 shows that correlations between these maximum and minimum temperatures have remained above 0.6 for all but the earliest years of the century (SILO excepted), and are mostly $>0.8$. Finally, although the rate of increase in maximum temperatures exceeds that of minimum temperatures, neither maximum nor minimum temperatures have increased at a rate commensurate with the increase in ring widths over the past decade (Fig. S8). Based on these data, the increase in observed growth cannot adequately be accounted for by differential increases in maximum and minimum temperatures at the Mt Read site (Fig. 2e,f). Of course, the critical caveat here is that the respective minimum and maximum temperature data adequately reflect temperatures at the site. As discussed above, this may not be the case, particularly for maximum temperatures.

More contentious among possible causes of accelerated growth is the vigorously debated $\mathrm{CO}_{2}$ fertilisation effect (Huang et al. 2007; Holtram and Winter, 2010). LaMarche et al. (1984) and Bunn et al. (2003) have hypothesised that the effect is greater at high elevation due to lower partial pressure of $\mathrm{CO}_{2}$, but Silva et al. (2010) argue that increases in basal area increment observed at high elevation sites are more consistent with increasing temperatures largely because carbon was not limiting at these sites in the first place (Körner, 1998). In a careful study of the isotopic content of the Mt Read tree-rings over the period 1795-1994, Pepper (1999) found an overall increase in water use efficiency (assimilationrate divided by stomatal conductance, $\mathrm{A} / \mathrm{g}$ ). This study exploited measurements of $\mathrm{CO}_{2}$ (Etheridge et al., 1996) and $\delta^{13} \mathrm{CO}_{2}$ (Francey et al. 1999) in air extracted from Law Dome ice core bubbles. A/g is related mainly to the difference in $\delta^{13} \mathrm{C}$ between the ice air and tree-rings on a time frame determined by the age resolution in ice core bubble air; the Law Dome ice core records are unique because of their high temporal resolution ( 10 to 20 years for $\left.\mathrm{CO}_{2}\right)$ and overlap with modern atmospheric monitoring. During active photosynthesis, convective mixing in the atmosphere means that the atmospheric composition at Mt Read closely matches that at the nearby Cape Grim Baseline monitoring station, which in turn closely matches the composition at Law Dome (Francey et al. 1984, 2013). Pepper's (1999) derivation of A/g suggested an increased assimilation rate over the observed period of $26 \%$ if $g$ was assumed constant; however, circumstantial evidence for increasing $\mathrm{g}$, particularly near the end of the record, amplifies the implied assimilation increase (Pepper, 1999). A recent re-evaluation and augmentation of the Francey et al. (1999) ice core $\delta^{13} \mathrm{C}$ data leads to a small decrease in the difference between ice core and modern records (Rubino et al., 2013), without significantly changing the lower limit to the increased assimilation rate. Even in the absence of isotope data for the tree-rings after 1994, it is plausible that physiological changes in the Huon pine, consistent with $\mathrm{CO}_{2}$ fertilisation, could make a contribution to recent ring-width increases. However, some recent studies have found that while water use efficiency has increased over recent decades, there have not been concordant increases in stem growth (Nock et al. 2011; Peñulus et al. 2011; Andreu-Hayles et al. 2011b). In also noting the lack of a clear effect on growth, Silva and Horwath (2013) have concluded that the common extrapolation of associations between leaf-level processes and $\delta^{13} \mathrm{C}$ from tree ring $\delta^{13} \mathrm{C}$ needs to be reevaluated. They argue that most of the trends noted in water use efficiency can be simply explained through methodological issues and that increases in water use efficiency are independent of changes in $\delta^{13} \mathrm{C}$ discrimination. Therefore, in the absence of information detailing how increased assimilation relates to increased ring widths, this hypothesis must remain speculative at this time.

An alternative hypothesis, the 'sink inhibition hypothesis' proposes that photosynthate investment limits are imposed by temperature (Körner and Paulsen, 2004). Under the sink inhibition hypothesis, temperature-limited sites such as Mt Read would exhibit growth increases even for small temperature increases because they would be better able to utilise photosynthate (Grace et al. 2002; Körner and Paulsen, 2004). Two local factors that could have reasonably contributed to increased growth (if the sink inhibition hypothesis is correct) are either warmer conditions and/ or a lengthening growing season. Intensification of the STR over southeastern Australia (Larsen, 2008; Larsen and Nicholls, 2009; Timbal and Drosdowsky, 2012, Fig. 6a), resulting in more frequent anticyclonic conditions (and more frequent occurrence of temperature inversions) over the growing season, would effectively increase temperatures (particularly maximum temperatures) at the site. Uncertainty over the appropriateness of a constant ELR and the precise nature of the impact of STR intensification on the inversion layer at this elevation also need to be considered here, especially since Buckley et al. (1997) have previously suggested that the temperature inversion may be related to differential climate responses in Huon pine at high and low elevation. It is possible that the greater than expected increase in growth is simply an artifact of temperature data that do not reflect a changing ELR over the last century. In this context, investigation of other updated Huon pine sites along an elevational gradient would be helpful.

The Tasmanian growing season has also increased by up to 16 days since 1950 (The Australian Bureau of Meteorology, http:// www.bom.gov.au/climate/). A greater number of months have also had mean temperatures of $\geq 8{ }^{\circ} \mathrm{C}$ since1970 than in the first part of the 20th Century (Fig. 6b) and growing degree days (GDD) have increased slightly since 1945 (Fig. 6c). Elsewhere, growing season length has been linked to variability in maximum latewood 
density (Vaganov et al. 1999) and earlywood cell size in Pinus leucodermis (Deslauriers et al. 2008). Deslauriers et al. (2008) found earlywood cell size was larger when the radial enlargement period was longer and latewood cell wall thickness was also greater for extended seasons.

While an appraisal of possible reasons for the decoupling of temperature and growth in the most recent decades is important, to simply focus on the most recent period when time-dependence occurs over the last century (Fig. 2e and f, 3-5), would be to pay 'unequal attention' to other instances of decoupling that exist (Esper and Frank, 2009). Critically, although intensification of the STR and an increased length of the growing season could be important factors related to increased growth in recent decades at the Mt Read site, changes over time in STR intensity and length of the growing season may well have affected the relationship between temperature and growth at other times in the past. For example, at the same time that growth appears to be have been less than would be expected based on temperature from the late 1940s through to the early 1960s (Fig. 2e, f), the number of months with a mean temperature $<8{ }^{\circ} \mathrm{C}$ was generally less than for the following period (Fig. $6 \mathrm{c}$ ). If the chronology had actually ended in about 1965, one might have concluded that divergence (sensu Esper and Frank, 2009) had occurred because the chronology under-represented temperature (Fig. 2e,f). Most recently, the 2009 summer temperature was high relative to growth for that year (this feature is largely responsible for the weakening relationship between temperature and growth at the end of the series shown in Fig. 5, and to a lesser extent, in Fig. 3). A continuation of this situation may result another decoupling not dissimilar to that which occurred in the $1950 \mathrm{~s} / 60 \mathrm{~s}$, or signal the end of the most recent decoupling. The individual occurrences of decoupling resulting in time-dependence reiterate the need to better understand factors contributing to that time-dependence, particularly since tree-ring width is not solely determined by temperature. While the unexplained variation in the ring width-temperature relationship may well be due to factors associated with the physical environment at the site, measurement issues or a combination of these factors, it may also be partly due to the stochastic variability that inevitably exists when two time series are not perfectly correlated with one another.

\subsection{Developing a better understanding of time-dependence}

If the reason for time-dependence between climate data and tree-ring chronologies is primarily related to responses of trees to their environment (rather than uncertainties in climate data and/or the chronology), process-based models may help unravel the underlying mechanisms driving varying response intensity (to temperature, for example). This is because process-based models explicitly recognise tree growth as a function of moisture availability and temperature, rather than simply focusing on a statistical relationship with temperature alone (Anchukaitis et al. 2006; Tolwinski-Ward et al. 2011; Vaganov et al. 2011). However, in order to be of greatest benefit these models should be used in conjunction with high-resolution (daily or better) data and attention to anatomical detail. High-resolution monitoring of growth processes and wood formation (eg. Rossi et al. 2006; Deslauriers et al. 2008) is already underway at Mt Read. This high resolution data and intra-ring anatomical detail (Körner and Paulsen, 2004; Rossi et al. 2008) is also expected to provide detailed information on the relevant threshold temperature for xylem development (cf. Anchukaitis et al. 2012), which will enable an assessment of whether a longer growing season is meaningfully related to the greater than expected growth at Mt Read for most of the past two decades.
Other types of chronologies such as $\delta^{18} \mathrm{O}$ (Brienen et al. 2012b) or wood property chronologies can also contribute information about moisture availability, drought and season length (Deslauriers et al. 2008; Drew et al., 2013). Further development and analysis of these types of chronologies based on the same samples but sensitive to differing environmental factors, should help reveal how and why relationships between trees and specific climate variables vary over time.

\subsection{Potential solutions to time dependence in chronologies}

The reason that time-dependence or divergence (sensu Esper and Frank, 2009) exist will necessarily inform the manner in which it is dealt with. For reconstruction purposes, possible sources of uncertainty surrounding a conclusion of time-dependence or divergence must be examined. In the case of the Mt Read chronology, uncertainties related to standardisation - an issue repeatedly raised (D'Arrigo et al., 2008; Büntgen et al. 2008; Esper and Frank, 2009; Esper et al. 2010) - would appear to be relatively small, although additional investigation may be useful. Uncertainty within the temperature data itself (unfiltered and low-pass; Figs. 3 and 5) is more difficult to resolve because a temperature reconstruction depends upon instrumental data in some form to calibrate and verify the model. In the case of Mt Read, the averaged mean temperature data set (Fig. 7) may be useful in this respect. Further work in development of gridded data sets may also lead to an improved ability to incorporate local and regional dynamics into these gridded surfaces, thus improving their quality.

Chronologies based on wood properties (e.g. cell wall thickness, tracheid radial diameter, microfibril angle) containing more stable spatio-temporal relationships with temperature (Allen et al. 2013) may also be key to reducing time-dependence between temperature and tree ring chronologies, although, once again, considerable work remains to be done. In addition, if strong evidence of $\mathrm{CO}_{2}$ fertilisation in long ring-width chronologies used for climate reconstruction purposes can be found, continuing use of those ringwidth chronologies would clearly be problematic because there is no analogue for these conditions, at least in the last millennium (Rubino et al., 2014). Therefore, should this situation arise, investigation of the sensitivity of alternative wood properties chronologies from these same sites to $\mathrm{CO}_{2}$ fertilisation may be a useful adjunct to development of long ring width chronologies.

\section{Conclusions}

Over the past two decades there has been a decoupling of temperature and growth at the Mt Read Huon pine site. Unlike the decoupling first observed by Jacoby and D'Arrigo (1995) in which ring widths underestimated temperature in recent decades, the Mt Read ring widths overestimate warm season temperature for the past two decades. However, because decoupling of growth and temperature is not limited to the most recent decades, we have not called this recent decoupling 'divergence'. Rather, we view the decoupling that has occurred in more recent years as a special case of general time-dependence. In this sense, it is abundantly clear that the conclusion that inferred ring-width-based temperatures over Tasmania and southeastern Australia for the past decade and a half have been higher than for any other period in the past 1000 years is a conditional one. It is conditional on the assertion that the relationship between temperatures and ring width has remained sufficiently stable over time. In order to be able to ascertain whether or not this is the case, access to high quality climate data is required. Here we have indicated that none of the individual data sets used in this study is ideal for climate reconstruction from the Mt Read site and that the temporal relationship between the chronology and 
temperature varies somewhat depending on which temperature series is used, and whether data is unfiltered, high-pass or low-pass filtered. Uncertainty in the climate data is related to a number of factors including relatively crude grid resolution in a region of highly variable topography, the relationship between minimum and maximum temperatures and the potentially inappropriate use of a constant lapse rate in compiling gridded data. Although the averaged temperature series may be a useful compromise for reconstruction purposes, detailed appreciation of any issues involved in averaging these data sets is likely required prior to its use for reconstruction purposes. At the same time, further investigation of process-based models with input from high-resolution monitoring and alternative types of chronologies (including $813 \mathrm{C}$ ) may improve understanding as to why time-dependence occurs if it is in fact related to the chronology rather than linked to uncertainties in the climate data. Notwithstanding this, the ability to assess hypotheses as to why time-dependence occurs depends on the accuracy of the available climate data. Similarly, although several hypotheses related to changes in climate may be consistent with increasing growth in recent decades, there is little value in attempting to attribute cause until there is strong evidence that the increased growth apparent in the chronology is not swamped by uncertainties inherent in the currently available temperature data.

\section{Acknowledgements}

We thank two anonymous reviewers whose comments have greatly improved this work. Michael Grose provided the AWAP data and Wasyl Drosdowsky kindly provided the Drosdowsky L-index based on eastern Australian stations. We thank David Pepper for advice concerning implied assimilation increases in the Mt Read trees related to the $\mathrm{CO}_{2}$ fertilisation effect. This research was supported by the Australian Research Council research grant DP 120104320 and Future Fellowship FT120100715 to PJB, and by Herman Slade foundation grant HSF 09/5 to DD, GD, KA and PJB. Parks Tasmania granted permission to resample the Mt Read site in early 2010. Michael Goddard and Scott Nichols assisted with editing.

\section{Appendix A. Supplementary data}

Supplementary data related to this article can be found at http:// dx.doi.org/10.1016/j.quascirev.2014.08.003.

\section{References}

Allan, R.J., Ansell, T.J., 2006. A new globally complete monthly historical mean sea level pressure data set (HADSLP2), 1850 - 2004. J. Climatol. 19, 5816-5842.

Allen, K.J., Drew, D.M., Downes, G.M., Evans, R., Cook, E.R., Battaglia, M., Baker, P.J. 2013. A strong regional signal in low elevation Huon pine. J. Quat. Sci. 28, 433-438.

Anchukaitis, K.K., Evans, M.N., Kaplan, A., Vaganov, E.A., Hughes, M.K., GrissinoMayer, H.D., Cane, M.A., 2006. Forward modeling of regional scale tree-ring patterns in the southeastern United States and the recent influence of summer drought. Geophys. Res. Lett. 33, L04705. http://dx.doi.org/10.1029/2005/ GL025050.

Anchukaitis, K.J., Breitenmoser, P., Briffa, K.R., Buchwal, A., Büntgen, U., Cook, E.R. D'Arrigo, R.D., Esper, J., Evans, M.N., Frank, D., Grudd, H., Gunnarson, B.E. Hughes, M.K., Kidyanov, A.V., Körner, C., Krusic, P.J., Luckman, B., Melvin, T., Salzer, M., Shashkin, A., Timmreck, C., Vaganov, E.A., Wilson, R.J.S., 2012. Tree rings and volcanic cooling. Nat. Geosci. 5, 836-837.

Andreu-Hayles, L., D'Arrigo, R.D., Anchukaitis, K.J., beck, P.S.A., Frank, D., Goetz, S. 2011a. Varying boreal forest response to Arctic environmental change at the Firth River, Alaska. Environ. Res. Lett. 6 http://dx.doi.org/10.1088/1748-9326/6/ $4 / 049502$.

Andreu-Hayles, L., Planells, O., Gutièrrez, E., Muntan, E., Helle, G., Anchukaitis, K.J. Schleser, G.H., 2011b. Long tree-ring chronologies reveal 20th century increases in water-use efficiency but no enhancement of tree growth at five Iberian pine forests. Glob. Change Biol. 17, 2095-2112.
Bradley, R.S., Keimig, F.T., Diaz, H.F., Hardy, D.R., 2009. Recent changes in freezing level heights in the Tropics with implications for deglacierization of high mountain regions. Geophys. Res. Lett. 36 http://dx.doi.org/10.1029/2009GRL037712.

Briffa, K.R., Schweingruber, F.H., Jones, P.D., Osborn, T.J., Harris, I.C., Shiyatov, S.G., Vaganov, E.A., Grudd, H., 1998. Tree tell of past climates: but are they speaking less clearly today? Philos. Trans. R. Soc. Lond. 353, 65-73.

Briffa, K.R., Osborn, T.J., Schweingruber, F.H., Jones, P.D., Shiyatov, S.G., Vaganov, E.A., 2002a. Tree-ring width and density data around the Northern Hemisphere: Part 1. Local and regional climate signals. Holocene 12, 737-757.

Briffa, K.R., Osborn, T.J., Schweingruber, F.H., Jones, P.D., Shiyatov, S.G., Vaganov, E.A., 2002b. Tree-ring width and density data around the Northern Hemisphere: Part 2, Spatio-temporal variability and associated climate signals. Holocene 12, 759-789.

Briffa, K.R., Osborn, T.J., Schweingruber, F.H., 2004. Large-scale temperature inferences from tree rings: a review. Global Planet. Change 40, 11-26.

Brienen, R.J.W., Gloor, E., Zuidema, P., 2012a. Detecting evidence for $\mathrm{CO}_{2}$ fertilization from tree ring studies: the potential role of sample biases. Glob. Biogeochem. Cycles 26, GB1025. http://dx.doi.org/10.1029/2011GB004143.

Brienen, R., Helle, G., Pons, T.L., Guyot, J.-L., Gloor, M., 2012b. Oxygen isotopes in tree rings are a good proxy for Amazon precipitation and El Niño-Southern oscillation variability. Proc. Natl. Acad. Sci. 109, 16957-16962.

Brodribb, T.J., Cochard, H., 2009. Hydraulic failure defines the recovery and point of death in water-stressed conifers. Plant Physiol. 149, 575-584.

Brodribb, T.J., Hill, R.S., 1998. The photosynthetic drought physiology of a diverse group of Southern hemisphere conifer species is correlated with minimum season rainfall. Funct. Ecol. 1293, 465-471.

Buckley, B.M., Cook, E.R., Peterson, M., Barbetti, M., 1997. A changing temperature response with elevation for Lagarostrobos franklinii in Tasmania, Australia. Clim. Change 36, 477-498.

Bunn, A.G., Lawrence, R.L., Bellante, G.J., Waggoner, L.A., Graumlich, L.J., 2003. Spatial variation in distribution and growth patterns of old growth strip-bark pines. Arct. Antarct. Alp. Res. 35, 323-330.

Büntgen, U., Frank, D., Wilson, R., Carrer, M., Urbinati, C., Esper, J., 2008. Testing for tree-ring divergence in the European Alps. Glob. Change Biol. 14, $2443-2453$

Cook, E.R., Peters, K.P., 1981. The smoothing spline: a new approach to standardizing forest interior tree-ring width series for dendroclimatic studies. Tree-Ring Bull. 41, 45-53.

Cook, E.R., Johnson, A.H., Blasing, T.J., 1987. Forest decline: modeling the effect of climate in tree rings. Tree Physiol. 3, 27-40.

Cook, E.R., Johnson, A.H., 1989. Climate change and forest decline: a review of the red spruce case. Water Air Soil. Pollut. 48, 127-140.

Cook, E.R., Bird, T., Peterson, M., Barbetti, M., Buckley, B., D'Arrigo, R., Fancey, R., Tans, P., 1991. Climatic change in Tasmania inferred from a 1089-year chronology of Huon Pine. Science 253 (5025), 696-698.

Cook, E.R., Bird, T., Peterson, M., Barbetti, M., Buckley, B., D'Arrigo, R., Francey, R., 1992. Climate change over the last millennium reconstructed from tree-rings. Holocene 2, 205-217.

Cook, E.R., Briffa, K.R., Meko, D.M., Graybill, D.A., Funkhouser, G., 1995b. The segment length curse in long tree-ring chronology development for paleoclimatic studies. Holocene 5, 229-237.

Cook, E.R., Francey, R.J., Buckley, B.M., D'Arrigo, R.D., 1996. Recent increases in Tasmanian Huon Pine from a subalpine stand: natural climate variability, $\mathrm{CO}_{2}$ fertilisation, or greenhouse warming? Pap. Proc. R. Soc. Tasman. 130, 65-72.

Cook, E.R., Buckley, B.M., D'Arrigo, R.D., Peterson, M.J., 2000. Warm-season temperatures since $1600 \mathrm{BC}$ reconstructed from Tasmanian tree rings and their relationship to large-scale sea surface temperature anomalies. Clim. Dyn. 16, 79-91.

Cook, E.R., Palmer, J.G., Ahmed, M., Woodhouse, C.A., Fenwick, P., Zafa, M.U., Wahab, M., Khan, N., 2013. Five centuries of Upper Indus River flows from tree rings. J. Hydrol. 486, 365-375.

Coppola, A., Leonelli, G., Salvatore, M.C., Pelfini, M., Baroni, C., 2012. Weakening climate signal since mid-20th century in European larch tree-ring chronologies at different altitudes from the Adamello-Presanella massif (Italian Alps). Quat. Res. 77, 344-354.

D'Arrigo, R.D., Kaufmann, R.K., Davi, N., Jacoby, G.C., Laskowski, C., Myeni, R.B., Cherubini, P., 2004. Thresholds for warming-induced growth decline at elevational tree line in the Yukon territory, Canada. Glob. Biogeochem. Cycles 18. http://dx.doi.org/10.1029/2004GB002249.

D'Arrigo, R.D., Wilson, R., Liepert, B., Cherubini, P., 2008. On the 'divergence problem' in northern forests: a review of the tree-ring evidence and possible causes. Global Planet. Change 60, 289-305.

D'Arrigo, R.D., Jacoby, G.C., Buckley, B.M., Sakulich, J., Frank, D., Wilson, R., Curtis, A., Anchukaitis, K., 2009. Tree growth and inferred temperature variability at the North American Arctic tree line. Global Planet. Change 65, 71-82.

Deslauriers, A., Rossi, S., Anfodillo, T., Saracino, A., 2008. Cambial phenology, wood formation and temperature thresholds in two contrasting years at high altitude in southern Italy. Tree Physiol. 28, 863-871.

Drosdowsky, W., 2005. The latitude of the subtropical ridge over eastern Australia: the L index revisited. Int. J. Climatol. 25, 1291-1299.

Drew, D.M., Allen, K.J., Downes, G.M., Evans, R., Battaglia, M., Baker, P.J., 2013. .Wood properties in a long-lived conifer reveal strong climate signals where ring width series do not. Tree Physiol. http://dx.doi.org/10.1093/treephys/tps111.

Esper, J., Frank, D., 2009. Divergence pitfalls in tree-ring research. Clim. Change 94, $261-266$ 
Esper, J., Frank, D., Büntgen, U., Verstege, A., Hantemirov, R.M., Kirdyanov, A.V., 2010. Trends and uncertainties in Siberian indicators of $20^{\text {th }}$ century warming. Glob. Change Biol. 16, 386-398.

Etheridge, D.M., Steele, L.P., Lagenfelds, R.L., Francey, R.J., Barnola, J.-M., Morgan, V.I., 1996. natural and anthropogenic changes in atmospheric $\mathrm{CO}_{2}$ over the last 1000 years from air in Antarctic ice firn. J. Geophys. Res. 101, 4115-4128.

Franceshini, T., Bontemps, J.-D., Leban, J.-M., 2012. Transient historical decrease in earlywood and latewood density and unstable sensitivity to summer temperature for Norway spruce in northeastern France. Can. J. For. Res. 42, 219-226.

Francey, R.J., Barbetti, M., Bird, T., Beardsmore, D., Coupland, W., Dolezal, J.E., Farquhar, G.D., Flynn, R.G., Fraser, P.J., Gifford, R.M., Goodman, H.S., Kunda, B., McPhail, S., Nanson, G., Pearman, G.I., Richards, N.G., Sharkey, T.D., Temple, R.B., Weir, B., 1984. Isotopes in Tree Rings. Commonwealth Science and Industrial Research Organisation, Australia.

Francey, R.J., Allison, C.E., Etheridge, D.M., Trudinger, C.M., Enting, I.G., Leuenberger, M., Lengenfelds, R.L., Michel, E., Steele, L.P., 1999. A 1000-year high precision record of $\delta^{13} \mathrm{C}$ in atmospheric $\mathrm{CO}_{2}$. Tellus Ser. B 51, 170-193.

Francey, R.J., Trudinger, C.M., van der Schoot, M., Law, R.M., Krummel, P.B., Langenfelds, R.L. Steele, L.P., Allison, C.E., Stavert, A.R., Andres, R.J. Rödenbeck, C., 2013. Atmospheric verification of anthropogenic $\mathrm{CO}_{2}$ emission trends. Nat. Clim. Change 3, 520-524.

Frank, D., Büntgen, U., Böhm, R., Maugeri, M., Esper, J., 2007. Warmer early instrumental measurements versus colder reconstructed temperatures: shooting at a moving target. Quat. Sci. Rev. 26, 3298-3310.

Fritts, H.C., 1976. Tree Rings and Climate. Academic Press, London.

Gedalof, Z., Berg, A., 2010. Tree ring evidence for limited direct $\mathrm{CO}_{2}$ fertilization of forests over the 20th century. Glob. Biogeochem. Cycles 24, GB3027 doi: 10.1029.2009GB003699.

Gotway, C.A., Young, L.J., 2002. Combining incompatible spatial data. J. Am. Stat. Assoc. 97, 632-648.

Grace, J., Berninger, F., Nagy, L., 2002. Impacts of climate change on the tree line. Ann. Bot. 90, 537-544.

Grudd, H., 2008. Torneträsk tree-ring width and density Ad 500 - 2005: a test of climatic sensitivity and a new 1500-year reconstruction of north Fennoscandian summers. Clim. Dyn. 31, 843-857.

Gurskaya, M., Hallinger, M., Singh, J., Agafonov, L., Wilmking, W., 2012. Temperature reconstruction in the $\mathrm{Ob}$ river valley based on ring widths of three coniferous species. Dendrochronologia 30, 302-309.

Harvey, A.C., 1989. Forecasting, Structural Time Series and the Kalman Filter. Cambridge University Press, Cambridge, p. 554.

Holtram, J.A.M., Winter, K., 2010. Elevated $\left[\mathrm{CO}_{2}\right]$ and forest vegetation: more a water issue than a carbon issue? Funct. Plant Biol. 37, 694-702.

Huang, J.-G., Bergeron, Y., Denneler, B., Berninger, F., Tardif, J., 2007. Response of forest trees to increased atmospheric $\mathrm{CO}_{2}$. Critical Rev. Plant Sci. 26, 265-283.

IPCC, 2007. IPCC Fourth Assessment Report Climate Change 2007. In: Working Group 1 Report: the Physical Science Basis. IPCC. http://www.ipcc.ch/ publications and data/publications and data reports.shtml.

Jacoby, G.C., D'Arrigo, R.D., 1995. Tree ring width and density evidence of climatic and potential forest change in Alaska. Glob. Biogeochem. Cycles 9, 227-234.

Jeffrey, S.J., Carter, J.O., Moodie, K.B., Beswick, A.R., 2001. Using spatial interpolation to construct a comprehensive archive of Australian climate data. Environ. Model. Softw. 66, 309-330.

Jones, D., Wang, W., Fawcet, R., 2009. High-quality spatial climate data sets for Australia. Aust. Meteorol. Oceanogr. J. 58, 233-248.

Juday, G.P., Alix, C., 2012. Consistent negative temperature sensitivity and positive influence of precipitation on growth of flood plain Picea glauca in interior Alaska. Can. J. For. Res. 42, 561-573.

Kirkpatrick, J.B., Nunez, M., Bridle, K., Chladil, M.A., 1996. Explaining a sharp transition from sedgeland to alpine vegetation on mount Sprent, southwest Tasmania. J. Veg. Sci. 7, 763-768.

Körner, C., 1998. A re-assessment of high elevation treeline positions and their explanation. Oecologia 115, 445-459.

Körner, C., Paulsen, J., 2004. A world-wide study of high altitude treeline temperatures. J. Biogeogr. 31, 713-732.

LaMarche Jr., V.C., Graybill, D.A., Fritts, H.C., Rose, M.R., 1984. Increasing atmospheric carbon dioxide: tree ring evidence for growth enhancement in natural vegetation. Science 225, 1019-1021.

Larsen, S.H., 2008. Australian winter anticyclonicity, 1850-2006. J. Geophys. Res. 113 http://dx.doi.org/10.1029/2007JD008873.

Larsen, S.H., Nicholls, N., 2009. Southern Australian rainfall and the subtropical ridge: variations, interrelationships and trends. Geophys. Res. Lett. 36 http:// dx.doi.org/10.1029/2009GRL037786.

Leal, S., Eamus, D., Grabner, M., Wimmer, R., Cherubini, P., 2008. Tree rings of Pinus nigra from the Vienna basin region (Austria) show evidence of change in sensitivity in the late 20th century. Can. J. For. Res. 38, 744-759.

Lloyd, A.H., Bunn, A.G., 2007. Responses of the circumpolar boreal forest to 20th century climate variability. Environ. Res. Lett. 2 http://dx.doi.org/10.1088/17489326/4/045013.

Martìn-Benito, D.M., del Rio, M., Cañellas, I., 2010. Black pine (Pinus nigra Arn.) growth divergence along a latitudinal gradient in Western Mediterranean mountains. Ann. For. Sci. 67, 401-413.

Melvin, T.M., Briffa, K.R., 2008. A "signal-free" approach to dendroclimatic standardisation. Dendrochronologia 26, 71-86.
Minder, J.R., Mote, P.W., Lundquist, J.D., 2010. Surface temperature lapse rates over complex terrain: lessons from the Cascade Mountains. J. Geophys. Res. 115, D14122. http://dx.doi.org/10.1029/2009JD013493.

Mitchell, T.D., Jones, P.D., 2005. An improved method of constructing a database o monthly climate observations and associated high-resolution grids. Int. J. Climatol. 25, 693-712.

Nicolussi, K., Bortenschlager, S., Körner, C., 1995. Increase in tree-ring width in subalpine Pinus cembra from the central Alps that may be $\mathrm{CO}_{2}$-related. Trees 9 , $181-189$.

Nock, C.A., Baker, P.J., Wanek, W., Leis, A., Grabner, M., Bunyavejchewin, S., Hietz, P. 2011. Long-term increases in intrinsic water-use efficiency do not lead to increased stem growth in a tropical monsoon forest in Thailand. Glob. Change Biol. 17, 1049-1063.

Paulsen, J., Weber, U.M., Körner, C., 2000. Tree growth near treeline: abrupt or gradual reduction with altitude? Arct. Antarct. Alp. Res. 32, 14-20.

Peñulus, J., Canadell, J., Ogaya, R., 2011. Increased water-use efficiency during the 20th century did not translate into enhanced tree growth. Global Ecol. Biogeogr. 20, 597-608.

Pepper, D.A., 1999. Investigation of the Long Term Physiological Response of Huon Pine (Lagarostrobos Franklnii) to Changes in Atmospheric $\mathrm{CO}_{2}$ and Climate Using Stable Isotopes (Unpublished PhD thesis). School of Biological Sciences, University of Sydney, p. 224.

Peterson, D.L., Arbaugh, M.J., Robinson, L.J., Derderian, B.R., 1995. Growth trends of whitebark pine and lodgepole pine in a subalpine Sierra Nevada forest, California, U.S.A. Arct. Alp. Res. 22, 233-243.

Rossi, S., Deslauriers, A., Anfodillo, T., 2006. Assessment of cambial activity and xylogenesis by microsampling tree species: an example at the alpine timberline. IAWA J. 27, 383-394.

Rossi, S., Deslauriers, Gricar, J., Seo, J.-W., Rathberger, C.B.K., Anfodillo, T., Morin, H., Levanic, T., Oven, P., Jalkanen, R., 2008. Critical temperatures for xylogenesis in conifers of cold climates. Global Ecol. Biogeogr. 17, 696-707.

Rubino, M., Etheridge, D.M., Trudinger, C.M., Allison, C.E., battle, M.O. Lengenfelds, R.L., Steele, L.P., Curran, M., Bender, M., White, J.W.C., Jenk, T.M. Blunier, T., Francey, R.J., 2013. A revised 1000 year atmospheric $\delta^{13} \mathrm{C}-\mathrm{CO}_{2}$ record from Law Dome and South Pole. J. Geophys. Res. Atmos. 118 http://dx.doi.org/ $10.1002 /$ jgrd.50668 (in press).

Seidel, D.J., Free, M., 2003. Comparison of lower-troposphere temperature climatologies and trends at low and high elevation radiosonde sites. Clim. Change 59, 53-74.

Silva, L.C.R., Anand, M., Letihead, M.D., 2010. Recent widespread growth decline despite increasing atmospheric CO2. PLoS ONE 5 (7). http://dx.doi.org/10.10371/ journal.pone.0011543.

Silva, L.C.R., Horwath, W.R., 2013. Explaining global increases in water uses efficiency: why have we overestimated responses to rising atmospheric $\mathrm{CO}_{2}$ in natural forest ecosystems? PLOSone. http://dx.doi.org/10.137/journal.pone. 0053089 .

Strömgren, M., Linder, S., 2002. Effects of nutrition and soil warming on stemwood production in a boreal Norway spruce stand. Glob. Change Biol. 8, 1195-1204.

Thompson, L.G., Mosley-Thompson, E., Davis, M.E., Henderson, K., Mashiotta, T.A., 2003. Tropical glacier and ice core evidence of climate change on annual to millennial time scales. Clim. Change 59, 137-155.

Timbal, B., Drosdowsky, W., 2012. The relationship between the decline of south eastern Australian rainfall and the strengthening of the subtropical ridge. Int. J. Climatol. 33, 1021-1034.

Tolwinski-Ward, S., Evans, M.N., Hughes, M.K., Anchukaitis, K.J., 2011. An efficien forward model of the climate controls on interannual variation in tree-ring growth. Clim. Dyn. 36, 2419-2439.

Vaganov, E.A., Hughes, M.K., Kidyanov, A.V., Schweingruber, F.H., Silkin, P.P., 1999 Influence of snowfall and melt timing on tree growth in subarctic Eurasia. Nature 400, 149-151.

Vaganov, E.A., Anchukaitis, K.J., Evans, M.N., 2011. How well understood are the processes that create dendroclimatic records? A mechanistic model of the climatic control on conifer tree-ring growth dynamics. Ch. 3. In: Hughes, M.K. Swetnam, T., Diaz, H. (Eds.), Dendroclimatology Progress and Prospects, Developments in Paleoenvironmental Research, vol, 11. Springer Science+Business Media, New York.

Van Deusen, P., 1990. Evaluating time-dependent tree ring and climate relationships. J. Environ. Qual. 19, 481-488.

Villalba, R., Boninsegna, J.A., Veblen, T.T., Schmelter, A., Rubilis, S., 1997. Recent trends in tree-ring records from high elevation sites in the Andes of northern Patagonia. Clim. Change 36, 425-454.

Visser, H., Molenaar, J., 1988. Kalman filter analysis in dendroclimatology. Biometrics 44, 929-940.

Weijers, S., Alsos, I.G., Eidesen, P.B., Broekman, R., Loonen, M.J.J.E., Rozema, J., 2012 No divergence in Cassiope tetragona: persistence of growth response along a latitudinal gradient and under multi-year experimental warming. Ann. Bot. 110, 653-665.

Wilmking, M., D'Arrigo, R.D., Jacoby, G.C., Juday, G.P., 2005. Increased temperature sensitivity and divergent growth trends in circumpolar boreal forests. Geophys. Res. Lett. 32 http://dx.doi.org/10.1029/2005GRL023331.

Wilson, R., Luckman, B., 2002. Tree-ring reconstruction of maximum and minimum temperatures and the diurnal temperature range in British Columbia, Canada. Dendrochronologia 20, 1-12. 
Wilson, R., Luckman, B., 2003. Dendroclimatic reconstruction of maximum temperatures from upper treeline sites in interior British Columbia, Canada. Holocene 13, 851-861.

Wilson, R., D'Arrigo, R.D., Buckley, B., Büntgen, U., Esper, J., Frank, D., Luckman, B., Payette, S., Vose, R., Youngblut, D., 2007. A matter of divergence: tracking recent warming at hemispheric scale using tree ring data. J. Geophys. Res. 112, D17103. http://dx.doi.org/10.1029/2006JD008318.

Wilson, R., Cook, E.R., D'Arrigo, R.D., Riedwyl, N., Evans, M.N., Tudhope, A., Allan, R., 2010. Reconstructing ENSO: the influence of methods, proxy data, climate forcing and teleconnections. J. Quat. Sci. 25, 62-78.
Young, G.H.F., Bale, R.J., Loader, N.J., McCarroll, D., Nayling, N., Vousden, N., 2012. Central England temperature since AD1850: the potential of stable carbon isotopes in British oak trees to reconstruct past summer temperatures. J. Quat. Sci. 27, 606-614.

Zhang, Y., Wilmking, M., 2010. Divergence growth responses and increasing temperature limitation of Qinghai spruce along an elevation gradient at the northeast Tibet Plateau. For. Ecol. Manag. 260, 1076-1082.

Zhang, Y., Wilmking, M., Gou, X., 2009. Changing relationships between tree growth and climate in Northwest China. Plant Ecol. 201, 39-50. 